\title{
Routine screening for intimate partner violence in public health care settings in Kenya: An assessment of acceptability
}

\author{
Chi-Chi Undie \\ Population Council \\ Catherine Maternowska \\ Margaret Mak'anyengo \\ Harriet Birungi \\ Population Council \\ Jill Keesbury \\ Population Council
}

See next page for additional authors

Follow this and additional works at: https://knowledgecommons.popcouncil.org/departments_sbsr-rh

Part of the Demography, Population, and Ecology Commons, Domestic and Intimate Partner Violence Commons, Family, Life Course, and Society Commons, International Public Health Commons, and the Women's Health Commons

How does access to this work benefit you? Let us know!

\section{Recommended Citation}

Undie, Chi-Chi, Catherine Maternowska, Margaret Mak'anyengo, Harriet Birungi, Jill Keesbury, and lan Askew. 2012. "Routine screening for intimate partner violence in public health care settings in Kenya: An assessment of acceptability," APHIA II OR Project in Kenya Technical Report. Nairobi: Population Council. 


\section{Authors}

Chi-Chi Undie, Catherine Maternowska, Margaret Mak'anyengo, Harriet Birungi, Jill Keesbury, and lan Askew 
TECHNICAL

REPORT

Routine screening for intimate partner violence in public health care settings in Kenya: An assessment of acceptability

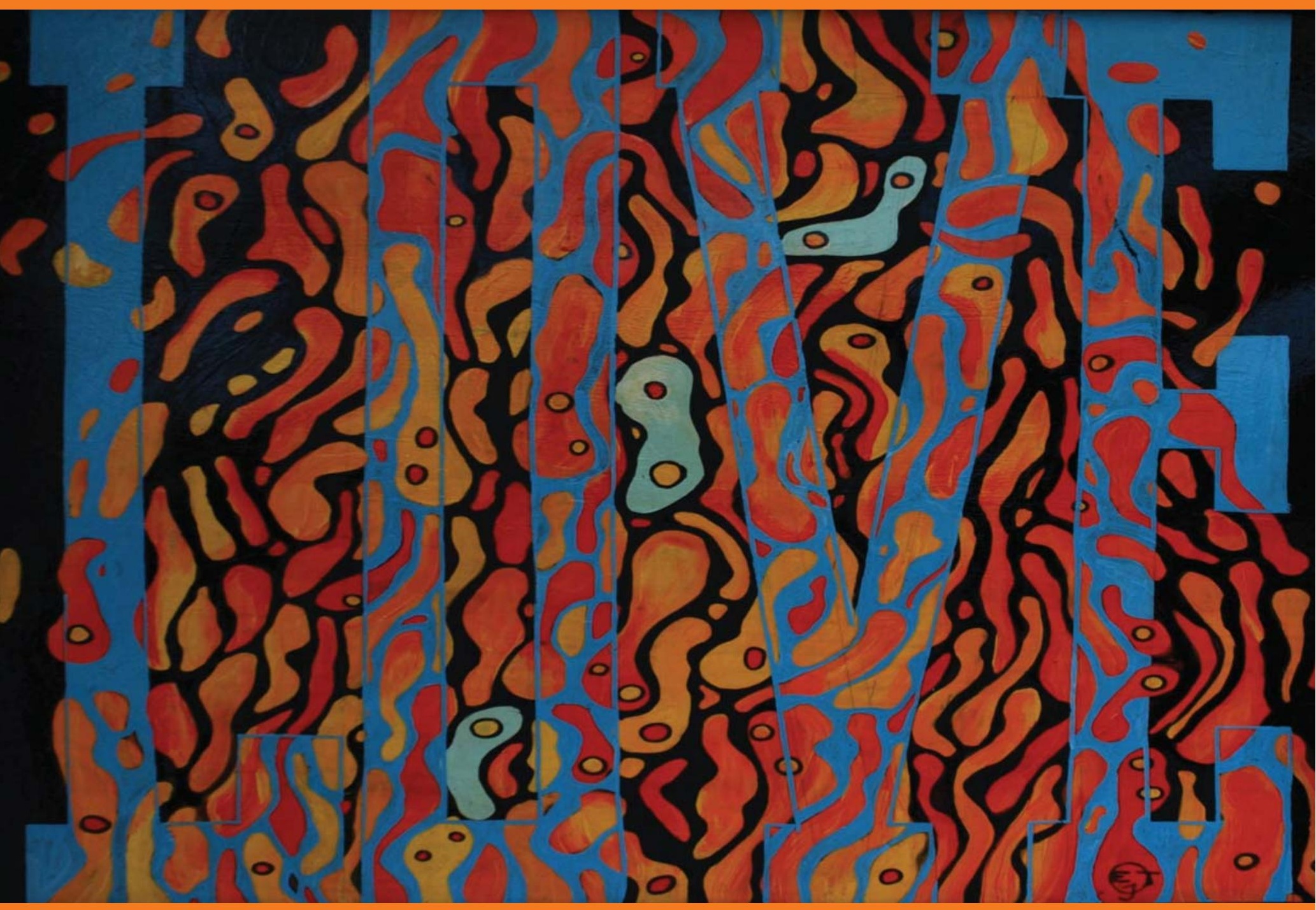




\section{Routine screening for intimate partner violence in public health care settings in Kenya:}

\section{An assessment of acceptability}

Chi-Chi Undie ${ }^{1}$, M. Catherine Maternowska ${ }^{2}$, Margaret Mak'anyengo ${ }^{3}$, Harriet Birungi ${ }^{1}$, Jill Keesbury ${ }^{1}$, Ian Askew ${ }^{1}$

\section{Population Council ${ }^{1}$}

Bixby Center for Global Reproductive Health, University of California, San Francisco and UNICEF/ESARO ${ }^{2}$

Kenyatta National Hospital ${ }^{3}$

March 2012 


\section{Acknowledgments}

This report is based on a study funded by the United States Agency for International Development (USAID)/Kenya Mission through a cooperative agreement (No. 623-A-00-09-00001-00) between the Mission and the Population Council. The study was also made possible through financial support from the Regional Swedish-Norwegian HIV and AIDS Team for Africa. The APHIA II Operations Research Project implemented the study in collaboration with the Kenyatta National Hospital (KNH).

We are grateful to our study respondents - clients and providers at $\mathrm{KNH}$ - for giving generously of their time to participate in the study, and deeply appreciate the contributions of the following $\mathrm{KNH}$ staff members: Mr. Richard Lesiyampe, Chief Executive Officer; Dr. Margaret Mak'anyengo, Head, Gender-Based Violence Recovery Centre; Dr. John Ong'ech, Head, Obstetrics and Gynaecology Department; Dr. David Bukusi, Head, Youth Centre, and Voluntary Counseling and Testing Centre; Dr. Peter Muiruri, Manager, Comprehensive Care Centre; and all members of KNH's Taskforce on Intimate Partner Violence.

We acknowledge the invaluable contributions of Irene Namai and Janerose Kweyu, who collected most of the data under this project. Our sincere thanks to our Population Council colleagues: Winnie Osulah and Janet Munyasya for administrative support; Joanne Gleason for reviewing an earlier draft of the report; Nancy Termini for reviewing the final draft of the report; and interns, Sylviah Nyamu and Bofa Itombra-Okoro, for participation in data collection and data analysis, respectively.

The Population Council confronts critical health and development issuesfrom stopping the spread of HIV to improving reproductive health and ensuring that young people lead full and productive lives. Through biomedical, social science, and public health research in 50 countries, we work with our partners to deliver solutions that lead to more effective policies, programs, and technologies that improve lives around the world. Established in 1952 and headquartered in New York, the Council is a nongovernmental, nonprofit organization governed by an international board of trustees.

www.popcouncil.org

This publication has been made possible with the generous support of the American people through USAID/Kenya, under the APHIA II Operations Research Project, a cooperative agreement No. 623-A-00-09-00001-00 between the Kenya Mission and the Population Council. The opinions expressed herein are those of the authors and do not necessarily reflect the views of USAID.

Cover painting: (C) 2004, Eirik Jarl Trondsen

Eirik Jarl Trondsen was born in Oslo, Norway, studied in Uganda, and worked with art in the Kibera slum of Nairobi and currently lives in Kenya. Contact ejtconsult@gmail.com. The painting on the cover page signifies love and relationships in a colorful and energetic world.

Suggested Citation: Chi-Chi Undie, M. Catherine Maternowska, Margaret Mak'anyengo, Harriet Birungi, Jill Keesbury, Ian Askew. 2012. Routine screening for intimate partner violence in public health care settings in Kenya: An assessment of acceptability. APHIA II OR Project in Kenya/ Population Council: Nairobi, Kenya.

Any part of this publication may be photocopied without permission from the publisher provided that copies are distributed without charge and that full source citation is provided. The Population Council would appreciate receiving a copy of any materials in which the text is used. 


\section{Table of Contents}

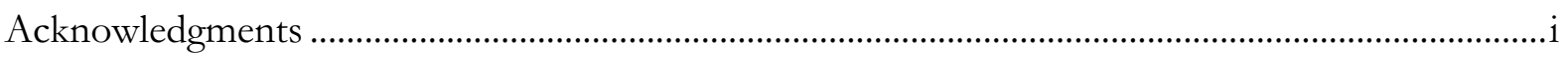

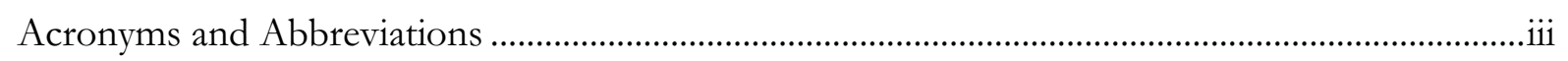

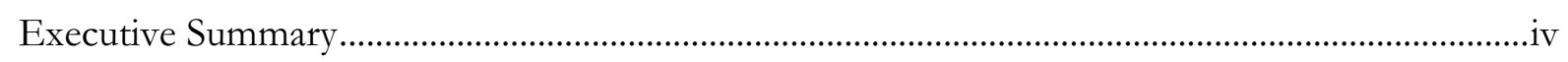

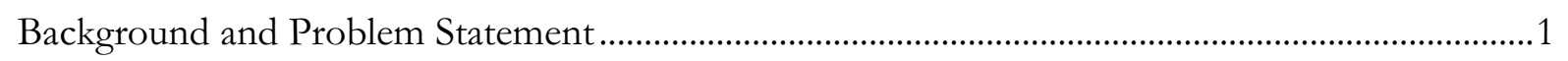

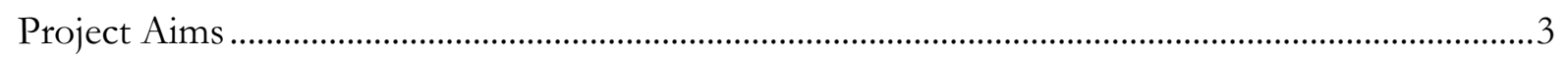

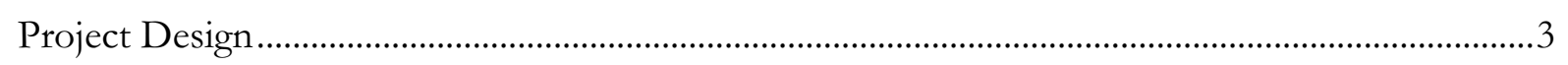

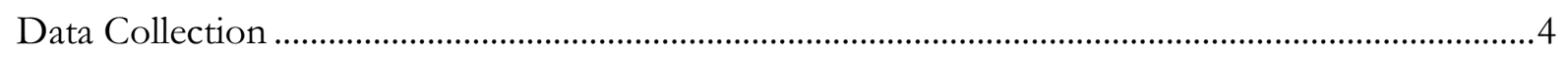

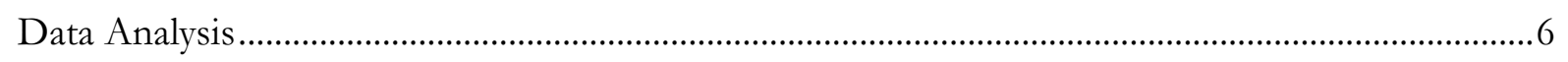

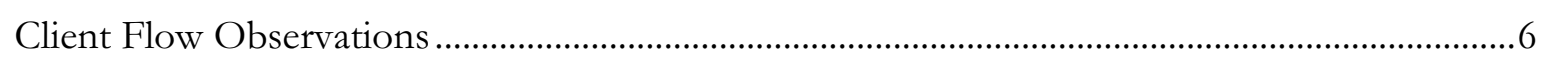

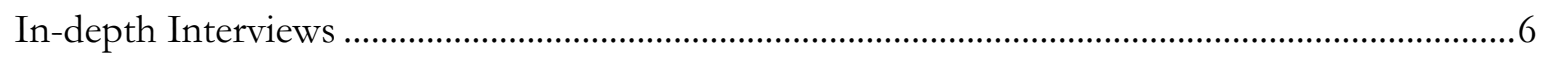

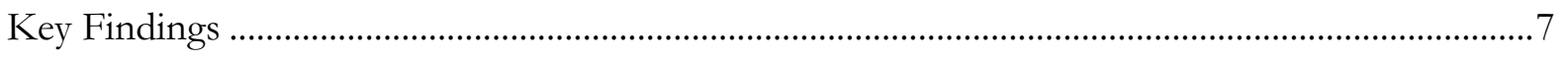

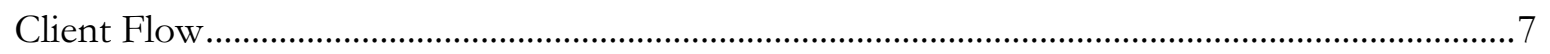

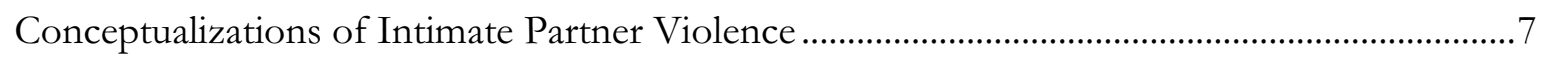

Provider and client perceptions of IPV prevalence .........................................................................11

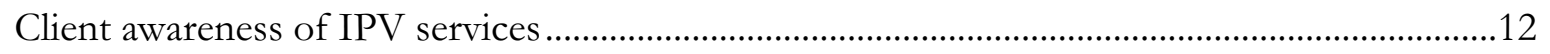

Perceived facilitators for IPV referral compliance ............................................................................12

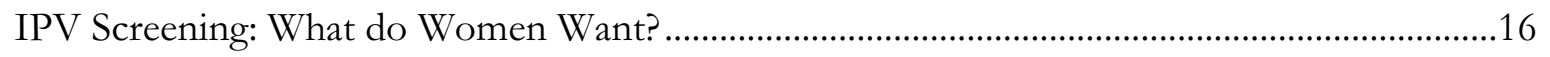

IPV Screening: Convergences between client and provider priorities .........................................19

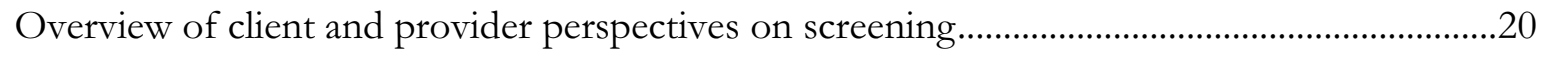

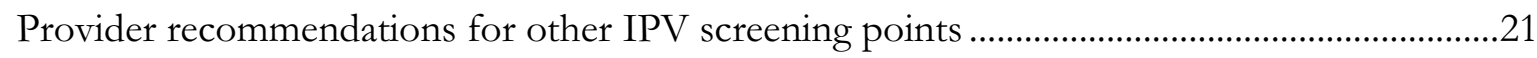

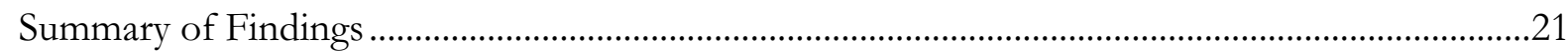

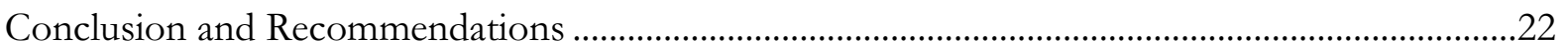

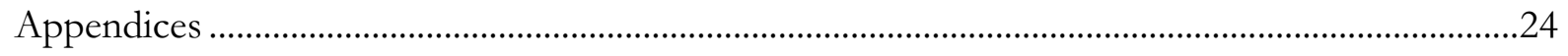

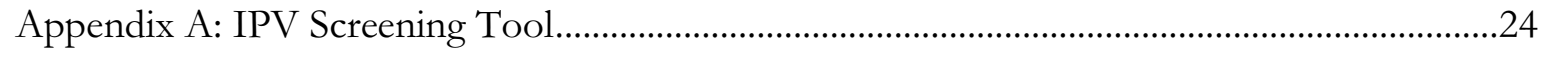

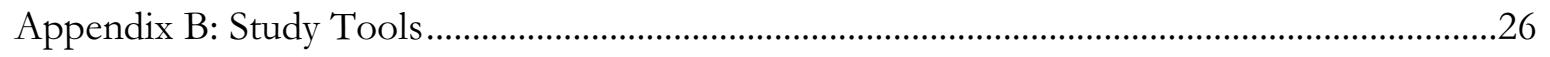




\section{Acronyms and Abbreviations}

$\begin{array}{ll}\text { AIDS } & \text { Acquired Immune Deficiency Syndrome } \\ \text { ANC } & \text { Antenatal Care } \\ \text { CCC } & \text { (HIV) Comprehensive Care Centre } \\ \text { FIDA } & \text { Federation of International Women Lawyers } \\ \text { GBV } & \text { Gender-Based Violence } \\ \text { GBVRC } & \text { Gender-Based Violence Recovery Centre } \\ \text { HIV } & \text { Human Immuno-Deficiency Virus } \\ \text { KNH } & \text { Kenyatta National Hospital } \\ \text { IPV } & \text { Intimate Partner Violence } \\ \text { NWH } & \text { Nairobi Women's Hospital }\end{array}$




\section{Executive Summary}

Although routine screening for intimate partner violence (IPV) is a current recommendation of several professional associations in industrialized countries, developing country contexts such as Kenya have yet to take on this task. There are good reasons for this hesitation, given that strong health systems should ideally be in place prior to the introduction of IPV screening. The current proliferation of one-stop Gender Based Violence (GBV) centers in African countries, however, now provides an opportunity to determine the acceptability of routine IPV screening. That violence has become an increasingly serious public health concern in the region emphasizes further the need for acceptability assessments around this issue. As most research on IPV screening has been conducted in developed countries, this study serves as one of the first in a developing country context to assess the acceptability of IPV screening from the perspective of providers and clients in public health care settings.

Drawing primarily on qualitative methods, the study used a descriptive case study design (involving semi-structured, in-depth interviews with clients and providers, and client flow observations) to assess the acceptability of screening for IPV. The study was conducted in Kenyatta National Hospital $(\mathrm{KNH})$, Nairobi - the oldest and largest public referral hospital in the East African region. The antenatal care clinic, the HIV comprehensive care centre, the Gender-Based Violence Recovery Centre, and the Youth Centre of KNH served as the specific study sites.

Findings from the study are summarized as follows:

1. There is considerable concurrence between providers and clients on the importance and relevance of screening and referrals for the care and treatment of violence. The single area of disconnect between providers and clients lies in the definition of IPV. Providers tended to cast IPV into the realm of sexual violence, while clients and survivors included the physical, economic, and emotional/psychological aspects of IPV as relevant, if not more common than sexual violence. This challenge could be easily remedied through trainings and raising advocacy around all aspects of violence and the services available in response.

2. IPV is perceived by clients and providers as being a highly prevalent issue in the lives of Kenyan women, with providers estimating that it is a lived experience of anywhere from a third to over half of their clients, an estimate supported by national DHS data.

3. Despite perceptions that IPV is extremely prevalent in the lives of women, few clients are aware of the existence of the Gender-Based Violence Recovery Centre at Kenyatta National Hospital. Yet, clients perceive that survivors of IPV are more likely to seek assistance in hospital settings than with family or friends.

4. Although compliance with referrals among clients is often linked to external factors that prompt and encourage follow-through, the study found that there are also important (and usually overlooked) internal factors that could serve to ensure improved IPV referral compliance.

5. Young people in this study emerged as a special group with slightly different needs from other clients. Their main concerns revolved around the need for the IPV screening process to be youth-friendly.

6. All providers and clients interviewed were of the opinion that screening for IPV is an important and useful undertaking that would be highly beneficial to women. Given the perceived importance of the issue, providers also gave recommendations for other departments within Kenyatta National Hospital where screening is needed, considering the estimated large number of IPV cases that are likely present in these settings. 
In conclusion, routine screening for IPV is acceptable to providers and clients at Kenyatta National Hospital. However, to be effective as a routine service, the system as it currently stands needs to be reinforced in specific ways, including greater assurance of confidentiality, more positive provider attitudes and higher respect for clients' rights. These weaknesses are typical for the quality of care for similar services provided within accredited public sector health facilities in Kenya.

Based on the results of this acceptability study, an IPV screening tool was developed in October 2011 by the Kenyatta National Hospital's IPV Taskforce in collaboration with the Population Council. This tool will be piloted in 2012, through a partnership between the Population Council and Kenyatta National Hospital, to assess the feasibility of administering it routinely in public health care settings to fully measure the success of the IPV screening program-the first of its kind on the African continent. 


\section{Background and Problem Statement}

Historically referred to as 'domestic violence,' intimate partner violence (IPV) describes physical, sexual, or psychological harm by a current or former intimate partner or spouse, and can occur among heterosexual and same-sex couples alike. ${ }^{1}$ Routine screening for intimate partner violence (IPV) is a current recommendation of several professional associations in industrialized countries such as the United States and the United Kingdom. Arguments in favor of IPV screening hold that quality of care is compromised as a consequence of failure to inquire about violence. Opportunities to remove women and children from harmful situations are also missed as a result. Although evidence points to the ability of screening to detect various forms of violence, much of the research in question has occurred outside developing country contexts. ${ }^{2}$

In developing countries, where integrated services exist, emphasis has been placed on training health care workers to address the immediate care and treatment procedures for sexual violence as an intervention strategy within hospitals and clinics. Routine screening for violence, through various points of entry into or within medical facilities, has been less of a priority. Yet, a review of IPV among couples in 10 developing countries ranked Kenya among the countries with the highest prevalence rate of reported sexual violence in current relationships $(15 \%)^{3}$. This finding corroborated that of a domestic violence survey in Kenya carried out by the Federation of Kenya Women Lawyers (FIDA) in 2002, indicating that the most common human rights violation in Kenya is domestic violence. ${ }^{4}$ More recently, the 2008/09 Kenya Demographic and Health Survey indicated that almost half (45\%) of 15-49 year old women reported having experienced either physical or sexual violence in their lifetime.

The consequences of IPV are often devastating, affecting survivors' physical health and mental well-being. Left untreated, exposure to violence can have profound impacts on core aspects of a survivor's emotional, behavioral, physical and social health. Violence has been shown to be closely correlated with poor reproductive health outcomes, including but not limited to unwanted pregnancy, premature labor and birth, as well as sexually transmitted diseases. Physical and sexual violence also simply affect survivors' overall quality of life, diminishing productivity and eroding self-esteem and worth, all of which impact negatively on families, especially children who are often observers of such victimization ${ }^{5}$.

Unequivocally, studies from around the world are also showing that HIV/AIDS and violence have a dangerous, complex relationship and may each increase the risk and impact of the other ${ }^{6}$. Research examining violence as an outcome of women's HIV status disclosure reveals that among women who disclose their HIV status, $3 \%$ to $15 \%$ report domestic violence. ${ }^{7}$ In a study

\footnotetext{
${ }^{1}$ National Institute of Justice (2007). Intimate Partner Violence. < http://www.nij.gov/topics/crime/intimatepartner-violence/>. Retrieved November 19, 2011.

2 Jewkes, R. (2002). Intimate partner violence: Causes and prevention. The Lancet 359”:1423-1429.

${ }^{3}$ Intimate Partner Violence among Couples in 10 DHS Countries: Predictors and Health Outcomes, USAID, Dec 2008.

${ }^{4}$ Sitawa, Kimuna \& Yanyi K. Djamba. "Gender Based Violence: Correlates of Physical and Sexual Wife Abuse in Kenya”, Published online: 30 January 2008, J Fam Viol. 2008.

${ }^{5}$ Kilonzo,N. "Post Rape services in Kenya Situation analysis", LVCT. 2003

${ }^{6}$ Further sources on this can be provided

7 World Health Organization. 2004a. Preventing violence: A guide to implementing the recommendations of the World report on violence and health. Geneva: WHO.
} 
of $324 \mathrm{HIV}$-positive women in Kenya, 19\% had experienced violence from their partner. ${ }^{8}$ Furthermore, research shows that 4\% of HIV infections in adolescents (13-19 years) in the country are a consequence of rape .

In 2007-2008, when post-election violence in Kenya triggered a mandatory national response to violence, several large health facilities instituted a medical response to forms of sexual violence, including gender-based violence and intimate partner violence. In addition, the recently published second edition of guidelines for the management of sexual violence in medical settings reflects an on-going commitment on behalf of the Government ${ }^{10}$. Yet, many gaps in services remain. Referrals between the community, police and medical sectors remain weak overall. Referrals within medical facilities where GBV services are nested appear to be equally as weak, with survivors lost to follow-up even within hospital premises. Furthermore, in most cases, the system that has been developed is geared toward responding to emergency medical treatment rather than follow-up or longer-term care, especially in the case of chronic violence common with IPV. Current models of service delivery, because they are based largely on immediate and emergency care, mainly address cases of rape and assault resulting in injuries. The fact that many gender-based violence centers are referred to as 'post-rape care' services may also be seriously limiting the ability of the health care system to capture all survivors of violence-and notably those experiencing chronic IPV.

From the survivor's perspective, routine screening may help identify victims early before violence escalates further, which has been shown to significantly reduce survivors' morbidity and mortality ${ }^{11}$. Some researchers argue that routine screening also improves sexual and reproductive health-related diagnosis, treatment, and counseling by helping providers to understand the underlying cause behind many conditions. Furthermore, in a social context where violence is widely unreported, screening may enhance access to existing services ${ }^{12}$. These issues, and the apparent failure of the current health system in Kenya to capture large proportions of survivors of violence, provide ample justification for testing the acceptability of IPV screening services in medical facilities.

\footnotetext{
${ }^{8}$ Watts, C. Mayhew, S. "Reproductive Health Services and Intimate Partner Violence: Shaping a Pragmatic Response In Sub-Saharan Africa”. International Family Planning Perspectives Volume 30, Number 4, 2004.

${ }^{9}$ Op cit Kilonzo 2003.

${ }^{10}$ MOPHS \& MOMS (2009). National Guidelines on Management of Sexual Violence in Kenya http://www.liverpoolvct.org/images/downloadable/NATIONALGUIDELINESONMANAGEMENTOFSV.p df.

${ }^{11}$ Heise L, Ellsberg M, Gottemoeller M. "Ending Violence Against Women.” Population Reports, Volume XXVII, number 4, Series L, Number 11, 1999.

12 Bott, S. Guedes, A. Claramunt MC. Güezmes,A. Improving the Health Sector Response to Gender-based Violence: A Resource Manual for Health Care Managers in Developing Countries. New York: IPPF, Western Hemisphere Region (IPPF/WHR). 2004.
} 


\section{Project Aims}

The overall goal of this project was to assess the acceptability of routine screening for intimate partner violence in Kenyan public health care settings.

Specifically, the project aimed to:

1. assess the acceptability of routine IPV screening from the perspective of health providers (including the willingness and capacity of health providers to implement routine IPV screening in clinical settings offering reproductive health and HIV services, and the potential barriers and facilitators to this process);

2. assess the acceptability of being asked questions around IPV from the perspective of female clients, and the extent to which this might encourage or discourage their use of GBV/IPV services;

3. describe client flow and referral systems for survivors of violence in selected sites;

4. design an appropriate tool for IPV screening.

\section{Project Design}

Drawing primarily on qualitative methods, the study used a descriptive case study design (involving semi-structured, in-depth interviews with clients and providers, and client flow observations in four sites - each studied as a separate 'case') to assess the acceptability of screening for IPV in public health care settings.

The study was conducted in Kenyatta National Hospital (KNH), Nairobi - the oldest and largest public district referral, teaching, and research hospital in the East African region, with an average annual outpatient attendance rate of 600,000 visits per year. ${ }^{13} \mathrm{KNH}$ brings with it certain advantages: the Gender-Based Violence Recovery Centre (GBVRC) at KNH, which offers comprehensive post-rape care services and attends to other forms of violence, is located within the hospital's Patient Support Centre, which is also home to KNH's Psychiatry Department. Given that IPV clients would be likely to need extended counseling; this was viewed as an ideal setting from which to effectively triage IPV clients screened from other departments, should the acceptability of routine IPV screening be established. The Patient Support Centre offers psychosocial support to special populations (such as substance abuse clients and HIV-positive clients), with GBVRC staff providing services across both centers (i.e., the GBVRC and the wider Patient Support Centre). As a result, there is already a cadre of staff at $\mathrm{KNH}$ accustomed to providing services to special populations. These considerations informed the selection of $\mathrm{KNH}$ as the overall study site.

\footnotetext{
${ }^{13}$ Mars Group (2007). The Kenyatta National Hospital. < http://www.marsgroupkenya.org/pdfs/Oct 07/Parastatals/Kenyatta National Hospital/THE KENYATTA NATIONAL HOSPITAL Mandate.pdf $>$.
} 


\section{Data Collection}

Within $\mathrm{KNH}$, four study sites were selected to serve as relevant locales from which findings would be compared, namely, the antenatal care (ANC) department, the HIV comprehensive care centre (CCC), the GBVRC, and the Youth Centre. ${ }^{14}$ A theory-driven sampling strategy ${ }^{15}$ was employed, as prior theoretical knowledge (specifically, the fact that studies show violence is often a feature in the lives of pregnant women, HIV-positive women, and youth, and the fact that current models of service provision to survivors in GBV clinics tend to overlook the issue of IPV) informed the selection of the study sites within $\mathrm{KNH}$.

The interview instruments were translated into the local language (Kiswahili), pre-tested, and adjusted accordingly. In addition, two research assistants with extensive experience in sexual and reproductive health-related data collection received training on the goals of the project, the content of the tools, data collection, ethics, and verbatim hand-recording of interviews over a five-day period. Sensitization on gender-based violence also formed a core part of the training.

Ethical and research clearance for the study were provided by the Institutional Review Board of the Population Council, the KNH/University of Nairobi Ethics and Research Committee, the National Ethical Review Committee of the Kenya Medical Research Institute, and the Kenya National Council for Science and Technology. Individual, written informed consent was obtained from all participants before conducting the interviews.

Data collection took place from April to June, 2011 and included client flow observations in ANC, CCC, and Youth Centre settings, as well as semi-structured, in-depth interviews with service providers and clients in ANC, CCC, GBVRC, and Youth Centre departments at KNH. Similar field guides were used for interviewing providers in all departments. Clients were also interviewed using the same qualitative tool, with slight modifications made to the field guide used to interview clients at the GBVRC (see Appendix for field guides used in this study). A total of 68 clients and 11 providers were interviewed, while 22 client flow consultations were conducted. Participants satisfying the following criteria were eligible for individual interviews:

- Female clients aged 18 and above that sought services at one of the four study sites during the data collection period.

- Providers, regardless of sex, fitting the pre-determined profile of providers to be interviewed that was generated prior to data collection.

\footnotetext{
${ }^{14}$ The Youth Centre at KNH is a youth-friendly clinic that provides reproductive health and HIV services to young people.

15 Miles, M.B. and Huberman, A.M. 1994. Qualitative Data Analysis: An Expanded Sourcebook. Thousand Oaks, CA: Sage.
} 
The pre-determined profile of providers to be interviewed (see Table 1) was generated to ensure that a range of provider perspectives was gathered, and that providers who were best-placed to provide perspectives on IPV screening were included in the study.

\begin{tabular}{|c|c|c|c|}
\hline \multirow{5}{*}{$\begin{array}{l}\text { Provider } \\
\text { Interviews }\end{array}$} & Where done? & With whom? & \multirow{5}{*}{$\begin{array}{l}\text { Topical areas of inquiry } \\
\text { - Understanding and perception of GBV and IPV } \\
\text { - Estimation of prevalence } \\
\text { - Awareness of GBV services within hospital } \\
\text { - }[\text { For CCC]: Understanding of intersection of HIV and } \\
\text { sexual violence } \\
\text { - Existing protocol for self-reported cases of physical, } \\
\text { emotional, and/or sexual violence } \\
\text { - Understanding of concept of routine screening } \\
\text { - Willingness and capacity to incorporate routine IPV } \\
\text { - screening within their department } \\
\text { - Foreseen management of sexual violence at 1st } \\
\text { - Suggestions for other potential screening points } \\
\text { - Recommendations for referral mechanisms } \\
\text { - Willingness to contribute to a larger study to assess } \\
\text { feasibility of routine screening } \\
\text { - Suggestions for membership on Hospital Research } \\
\text { Task Force }\end{array}$} \\
\hline & ANC Clinic & $\begin{array}{l}1 \text { Head of Dept. } \\
1 \text { Deputy nurse in } \\
\text { charge }\end{array}$ & \\
\hline & $\begin{array}{l}\text { Comprehensive } \\
\text { Care Clinic }\end{array}$ & $\begin{array}{l}1 \text { Psychologist } \\
1 \text { HIV Counselor }\end{array}$ & \\
\hline & GBVRC & $\begin{array}{l}1 \text { Head of Dept. } \\
1 \text { Psychologist } \\
1 \text { Social worker } \\
1 \text { Nurse counselor } \\
1 \text { Receptionist }\end{array}$ & \\
\hline & Youth Centre & $\begin{array}{l}1 \text { Head of Dept. } \\
1 \text { Nurse counselor }\end{array}$ & \\
\hline \multirow{5}{*}{$\begin{array}{l}\text { Client } \\
\text { Interviews }\end{array}$} & Where done? & With whom? & Topical areas of inquiry \\
\hline & ANC Clinic & 20 clients & \multirow{4}{*}{$\begin{array}{l}\text { - Understanding and perception of GBV and IPV } \\
\text { - Estimation of prevalence } \\
\text { sevel of awareness about existing services for } \\
\text { survivors of IPV - within the hospital and beyond }\end{array}$} \\
\hline & $\begin{array}{l}\text { Comprehensive } \\
\text { Care Clinic }\end{array}$ & 20 clients & \\
\hline & GBVRC & 8 clients & \\
\hline & Youth Centre & 20 clients & \\
\hline
\end{tabular}

Client flow observations: Client flow observations were conducted with a total of 22 clients across three study sites (the ANC (10 clients), CCC (6 clients), and Youth Centre (6 clients) - to gather information on average client waiting times and basic information on client movement from entry into, to exit from, the health care system.

A research assistant, armed with a client flow observation form (see Appendix), would engage with individual clients from the moment they entered the department concerned, recording the client's time of arrival, provided the client was willing to participate in this exercise. The research assistant would accompany the client for the duration of her $\mathrm{KNH}$ visit, recording the exact time spent at each service point, as well as the service point itself (e.g., reception/registration, weighing room, main provider room, pharmacy, and laboratory), and the path of the client through the services attended. The client and research assistant would sit together while in waiting areas (reception/registration), and the research assistant would wait for the client in the waiting area whenever the client was being attended to by a provider. The client would be observed until she left the hospital grounds, and the time of departure was also noted.

Client flow observations were not conducted at the GBVRC because it is housed in the same location as the Patient Support Centre and so it was difficult to distinguish clients that had come in for GBV services from those attending for other reasons. Given the sensitivity of the subject of IPV, it was considered ethically appropriate to refrain from engaging GBVRC clients in this particular aspect of the study. 
Although in the original study design, six client observations were to be conducted in each study site, a total of 10 client observations were carried out at the ANC, following a special request from the Head of Department, who was particularly interested in client flow issues within this setting.

In-depth interviews: Short, semi-structured, in-depth interviews assessed the acceptability of routine IPV screening from the perspective of providers and clients. The interviews explored issues of understanding of IPV as a component (or not) of GBV, perceptions of screening and its implications, and, in the case of providers, institutional capacity to screen and refer. A total of 11 provider and 68 client in-depth interviews were conducted across ANC, CCC, GBVRC, and Youth Centre settings at KNH.

Clients interviewed at the GBVRC were initially screened by a trained psychologist within the GBVRC for psychological readiness to participate in the study. Once psychological readiness was established, and if the client concerned was interested in the study and willing to be interviewed, she was referred to a trained research assistant for an interview. Fewer client interviews were conducted at the GBVRC than in any other study site due to the fact that most clients during the study period presented with severe trauma and were therefore not in a position to participate in the study. Table 1 above provides an outline of interviews conducted with providers and clients.

\section{Data Analysis}

\section{Client Flow Observations}

As previously noted, clients were observed from the moment they entered the department (ANC, CCC, or Youth Centre) until they left the hospital grounds. Research assistants recorded waiting times as well as the path of the client through the services attended. The number of points where the client stopped or interfaced with providers, and the client's movement within the hospital were recorded. Notes were also recorded to explain lengthy waiting times.

The analysis of client flow observation data involved calculating the average total time spent at $\mathrm{KNH}$, the average waiting time, and the percent waiting time for clients in each department.

\section{In-depth Interviews}

The in-depth interviews were hand-recorded verbatim by trained research assistants. By the end of each day, the hand-recorded interview transcripts were typed up in MS Word. Data were analyzed using content analysis techniques primarily, with codes developed and configured along lines of topical inquiry. During this process, however, themes that proved important for assessing IPV screening acceptability emerged, and also formed a part of the final analysis. Each study site constituted a separate 'case' in the analysis initially and this process of 'within-case analysis ${ }^{16}$ facilitated understanding of the individual narrative that developed from each site. This was followed by a 'cross-case analysis ${ }^{17}$ stage in which comparisons were made between the common, dominant themes emerging across the four study sites as well as across the two respondent groups (i.e., providers and clients). Variations from dominant themes were also sought and noted as part of the analysis. The ultimate goal in pursuing this multi-pronged route of analysis was to generate theory about 'what was happening' around perceptions of IPV

\footnotetext{
${ }^{16}$ Miles, M.B. and Huberman, A.M. 1994. Qualitative Data Analysis: An Expanded Sourcebook. Thousand Oaks, CA: Sage.

17 ibid.
} 
screening as revealed by the data, and the concomitant implications for IPV screening acceptability.

Consistent with the qualitative approach employed to assess each site and the perceptions of providers and clients, the study findings are a reflection of the interview respondents' perspectives. Thus, this report consists mainly of quotations that 'give voice' to the respondents across the four study sites, highlighting the main themes that were either deliberately investigated, or which emerged from the in-depth interviews. Where multiple quotations are employed to highlight a theme, an attempt is made to draw them from different study sites and/or respondent categories to demonstrate how each theme generalized across the study sites and participant types.

\section{Key Findings}

\section{Client Flow}

Client waiting times exceeding two hours are not uncommon and have been reported globally. ${ }^{18}$ An examination of client flow is particularly important as long waiting times could be seen by potential clients as a barrier to accessing IPV services, thus informing perceptions about the acceptability of these services.

Table 2 suggests that client waiting times form an inordinate proportion of clients' total visit time in the ANC, CCC, and Youth Centre, with the highest total amount of waiting time observed being spent at the CCC, and the lowest at the Youth Centre.
Table 2: Average total time and average waiting time per client visit in ANC, CCC, and Youth Centre

\begin{tabular}{|l|c|c|c|}
\hline & $\begin{array}{c}\text { Average total } \\
\text { time per visit }\end{array}$ & $\begin{array}{c}\text { Average } \\
\text { waiting time }\end{array}$ & $\begin{array}{c}\text { Percent time } \\
\text { spent waiting }\end{array}$ \\
\hline ANC & $3 \mathrm{hrs} 25 \mathrm{mins}$ & $1 \mathrm{hr} 43 \mathrm{mins}$ & $50 \%$ \\
\hline CCC & $1 \mathrm{hr} 37 \mathrm{mins}$ & $1 \mathrm{hr} 22 \mathrm{mins}$ & $84 \%$ \\
\hline Youth Centre & $1 \mathrm{hr} 54 \mathrm{mins}$ & $52 \mathrm{mins}$ & $45 \%$ \\
\hline
\end{tabular}

The waiting times among the six clients observed at the CCC can be explained by the fact that CCC clients tended to have several different points of contact at the CCC within the same visit (e.g. from reception to cashier, to reception to weighing room, to reception to main provider room, to reception to pharmacy, to reception to physiotherapy room). Clients observed at the Youth Centre generally waited for about an hour after registering if they had come for a counseling visit, unlike their peers who had come to the Youth Centre for Voluntary Counseling and Testing. The latter tended to require relatively shorter waiting times. New patient visits also took much longer than repeat client visits. ANC waiting times varied depending on how many doctors were on duty at any given time.

\section{Conceptualizations of Intimate Partner Violence}

Conceptualizations are important as they inform functioning, and structure perceptions and interactions. ${ }^{19}$ The concepts that providers and clients hold regarding IPV therefore matter, as they could have a bearing on provider delivery and client receipt of IPV screening. Erroneous

$18 \mathrm{MSH}$ (2006). Managing Quality and Clinical Services.

$<$ http://erc.msh.org/mainpage.cfm?file=2.2.3.htm\&module=quality\&language=English $>$.

${ }^{19}$ G. Lakoff \& M. Johnson (2003). Metaphors we live by. Updated edition. Chicago: University of Chicago Press. 
conceptualizations of IPV on the part of providers, for example, could result in negative attitudes toward survivors, or in a lack of respect for survivor confidentiality. On the other hand, provider and client conceptualizations of IPV as a trivial issue, for instance, could impact negatively on their willingness to screen or be screened for IPV. The ways in which providers and clients conceptualize intimate partner violence were therefore considered an important area of investigation in this acceptability study.

\section{Provider conceptualizations of IPV}

Although some providers clearly had a comprehensive understanding of IPV, the majority of providers conceptualized intimate partner violence as sexual violence in particular. Indeed, for some, the two terms were actually synonymous. Although this conceptualization is not totally inaccurate (as sexual violence can indeed be a component of IPV), it does suggest that provider understandings of the term were lacking:
[IPV] could involve doing things you don't want to do - being forced. Like being forced to have sex (Provider, ANC).
IPV is different [from GBV] because it's more of a sexual ... more of somebody having sex with another (Provider, $A N C$ ).
W] hen I talk about GBV, I think of sexual violence. ... IPV to me sounds like it is about two people who are in an intimate relationship - one that's ongoing - unlike GBV, where the violence can be outside an intimate relationship (Provider, CCC).

Furthermore, there were indications that the term 'intimate partner violence' was semantically confusing for many providers. Historically referred to as 'domestic violence,' the term 'intimate partner violence' emerged to refute the notion that violence between partners occurs solely within the domestic sphere, and to be more inclusive of the range of intimate relationships (e.g., heterosexual and same sex; civil union and domestic partners; dating relationships among heterosexual and same-sex couples, whether youth or older people, etc.). It is noteworthy that interviews with providers were conducted in English, while interviews with clients were conducted in Kiswabili. The confusion inherent in the term 'intimate partner violence' for many providers is illustrated by the quotes below:

When I look at GBV, it's more of really violent and physical, but [IPV] is more emotional, psychological (Provider, CCC).

What comes to mind when I think about IPV is] people who are in a relationship, perhaps living together. Mostly physical violence, although there are emotional and financial, which are silent. Sexual is the major [kind of violence in regard to IPV], but it doesn't come to mind because of the term 'intimate.' Because with [the term] 'intimate', perhaps you've consented. And our culture doesn't believe in sexual violence within a couple, though it exists. Even they [clients] rarely report that (Provider, GBVRC).

I usually ... think [IPV] is about sexual issues. I relate [the term] 'intimate' with sex (Provider, Youth Centre).

The subconscious association that most providers tended to make between IPV and sexual violence, as opposed to a range of violence forms, may be interpreted historically in terms of the establishment of the GBVRC. Founded in 2006, the GBVRC was re-launched in 2008 in response to a dismal period of post-election violence in Kenya (from late 2007 to early 2008), involving national media, non-governmental organizations, and donor attention to incidents of sexual violence in particular. As a provider explained, "Many people came, [funding services for] sexual violence, and so the physical was ignored. But if a proper survey is done, physical violence is more [prevalent] than sexual [violence]" (Provider, GBVRC). This assertion is corroborated by another provider, who 
demonstrated how services for sexual violence survivors were privileged over those for physical violence in the GBVRC context:

Out-patient services [at the GBVRC] are free for sexual abuse cases, but not for physical abuse. We used to have funders that used to help waive the fees, but they're no longer there. Psychosocial services are free for sexual abuse only, but for physical abuse, counseling costs ksh 200 per session (Provider, GBVRC).

This well-intentioned focus on sexual violence appears to have set the tone for how the GenderBased Violence Recovery Centre has come to be perceived among Kenyatta National Hospital's own staff, and possibly, among outsiders - i.e., as a centre with a primary focus on sexual violence survivors. In the words of another provider:

A lot of the $[G B V R C]$ services are dealing with post-rape. Counseling and psychological services exist, but post-rape care is given the most attention. Violence is beyond just rape, so we haven't given the full range of violence enough attention. Other things haven't been embraced as much. We probably have counseling, but in the context of post-rape care.... You need to talk to the GBVRC because they're only thinking of rape (Provider, ANC).

It is plausible that this primary focus on sexual violence has inadvertently served to dissuade providers from identifying other forms of violence among their clients.

\section{Client conceptualizations of IPV}

Clients were asked in Kiswabili if they knew of anyone experiencing IPV, and if so, the specific kind(s) of IPV involved.

Their responses to these questions indicate that clients tended to conceptualize IPV in two main ways: 1) IPV was conceptualized by clients as being multi-faceted, and 2) IPV was conceptualized as being complex, with interconnections between the

\begin{tabular}{|l|c|c|c|c|c|}
\hline \multicolumn{6}{|c|}{ Table 3: Client conceptualizations of IPV (number of times alluded to) } \\
\hline & $\begin{array}{c}\text { No. of clients } \\
\text { interviewed }\end{array}$ & Physical & Emotional & Economic & Sexual \\
\hline ANC & 20 & 7 & 7 & 7 & 0 \\
\hline CCC & 20 & 14 & 11 & 6 & 0 \\
\hline $\begin{array}{l}\text { Youth } \\
\text { Centre }\end{array}$ & 20 & 10 & 10 & 4 & 2 \\
\hline Total & 60 & $\mathbf{3 1}$ & $\mathbf{2 8}$ & $\mathbf{1 7}$ & $\mathbf{2}$ \\
\hline \multicolumn{7}{|c|}{ Multiple responses were allowed. } \\
\hline
\end{tabular}
various forms of violence.

In stark contrast to the narrower definition offered by several providers, IPV was seen as a multi-faceted phenomenon that could be physical, emotional/psychological, economic, and sexual in nature. When asked whether they knew of anyone experiencing IPV, ${ }^{20}$ the majority of examples cited by clients centered on physical and emotional/psychological violence, with few instances of sexual violence cited. Examples of emotional/psychological violence featured prominently, and all examples related to verbal abuse, threats/intimidation, and forced isolation were grouped within the 'psychological/emotional violence' category during analysis. Examples of emotional/psychological violence included verbal abuse (10 references), abandonment (6), infidelity (6), intimidation (4), and forced isolation (2).

Unexpectedly, economic violence (defined, for instance, by a partner's refusal to provide money for food, health care, etc., or by a partner appropriating all of one's income) also formed a major component of clients' conceptualizations of violence.

\footnotetext{
20 This question was not posed to GBVRC clients as it was considered too sensitive for this particular population. See Appendix for all field guides used in this study.
} 
Sexual violence examples were cited the least among the 60 clients (in the ANC, CCC, and Youth Centre) asked whether they knew of anyone experiencing IPV (and, if so, what kind), and these examples of sexual violence were offered by Youth Centre clients only. It is highly plausible that sexual violence might have been more difficult for respondents in general to talk about given that this form of violence is often highly stigmatized in Kenyan society compared to other forms, and thus less likely to be revealed. However, this finding also highlights a possible disconnect between the manner in which the GBVRC has inadvertently been cast, and conceptualizations of violence on the part of potential clients.

Intimate partner violence, from the perspective of clients, was also conceptualized as being a complex phenomenon. In other words, clients' narratives on the subject indicate that various forms of violence are often inter-related, with a survivor rarely experiencing a sole form of violence at a time; rather, several forms of violence tend to occur simultaneously. Figure 1 provides a pictorial representation of this conceptualization, depicting the overlapping relationships between the forms of violence as presented by clients, and the frequency with which each type of violence was mentioned.

Figure 1: Pictorial representation of client conceptualizations of IPV

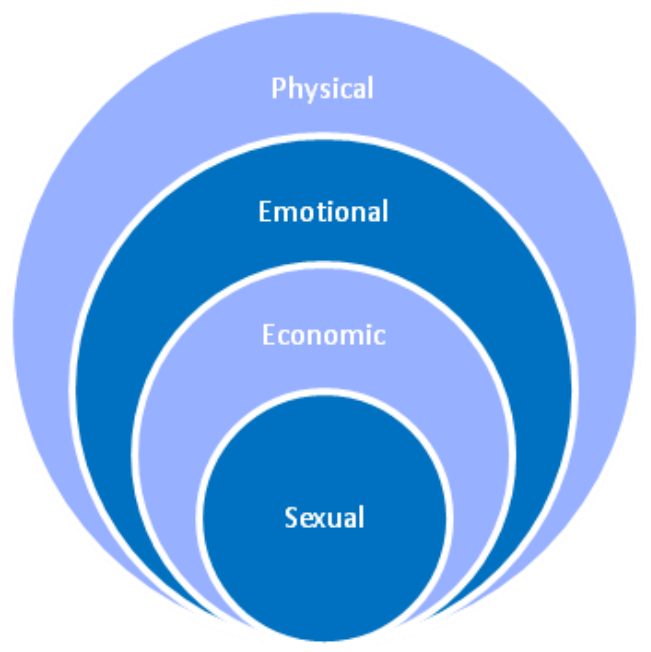

The following quotations are examples of how respondents presented various forms of violence concurrently:

I have a friend who shares with me and she tells me that the husband does not assist her at all when it comes to financial matters and he also abuses her physically by beating her, and the husband doesn't like her talking or being in the company of other women (Client, $A N C$ ).

My step-brother is very abusive towards [his wife]. She's beaten and she's not normally given any money.... After giving birth to her second baby, he demanded to have sex with her after just about two weeks, when her wounds were still fresh. ... But you know, she cannot do anything [about it]. She only reached class 8 and she depends on him for everything (Client, Youth Centre).

I have a friend whose husband ... is a violent person [.] She is abused verbally, [he] chases her away from the bouse together with the child, and sometimes they sleep out in the cold and he also threatens to kill [them]. He ... makes the environment not suitable for cooking, making them go to bed hungry (Client, CCC). 


\section{Provider and client perceptions of IPV prevalence}

The extent to which perceptions of IPV prevalence are shared between providers and clients was examined as a step toward determining the usefulness of IPV screening from the perspectives of these respondents. Despite the absence of a formal IPV screening program at $\mathrm{KNH}$, daily interaction with clients led providers, across the board, to perceive that IPV was a common experience among their clients. Indeed, the perceived scale of the problem had caused some to begin considering the introduction of screening. In the words of one provider: "[Screening] is done on suspicion, not routinely. But concerns have been expressed over the last couple of weeks so we can see if we can start putting together something - a couple of questions which would help us see if there's any violence" (Provider, Youth Centre). Formalizing the procedures could potentially be effective. Providers estimated that anywhere from a third to half (or more) of their clients probably experience IPV:

Quite a number of the clients we see here - probably even 1 in 2 - go through this [IPV]" (Provider, ANC).

In a day, if I have 5 patients and 3 [of them] are women, at least one will present with violence (Provider, CCC).

It's overwhelming. And that's based on my experience in the ward, in the Youth Centre, and even in the community (Provider, Youth Centre).

There was also a growing concern among providers about IPV in the lives of Kenyatta National Hospital staff in general. As some providers indicate below:

$[W]$ ith the patients, clearly, it [IPV] comes out ... But another scenario that I'm worried about has been more about staff. There seems to be a lot of IPV among the staff (Provider, Youth Centre).

This [IPV] is what we see here, even among our own staff ... But most women aren't coming here [to the GBVRC]. There are many women going through this (Provider, GBVRC).

The prevalence ${ }^{21}$ of intimate partner violence was also perceived as high by the vast majority of clients interviewed, as the following quotes demonstrate:

I think many are experiencing it because many of my friends tell me stories of how their boyfriends make them do things which they don't want to do (Youth Centre).

From what I have observed, very many women in Kenya tend to experience violence, though majority have never come up to say that they have been or are being abused by their husbands, in order to keep the relationship or marriage (Client, $A N C$ ).

I think that a majority of them are going through it, but some are suffering in silence. When you meet together with other women, you will hear them talking about it and you realize that you are not the only one going through such things (Client, CCC).

Overall, the study findings confirm the significance of IPV from the perspective of providers and clients alike, and indicate considerable convergence of the perceived significance and prevalence of IPV across among respondent groups. The challenge will be to break the 'suspicions' and silence that disable clients from empowering themselves.

\footnotetext{
${ }^{21}$ Clients were asked in Kiswahili: "From what you've observed, how much would you say women in Kenya tend to experience IPV?"
} 


\section{Client awareness of IPV services}

Given the widespread perception of IPV as a prevalent issue, it was important to also determine whether clients were aware of places that those experiencing IPV could go to for help.

Respondents were more likely to mention organized, official services - specifically, FIDA [the Federation of International Women Lawyers], the Nairobi Women's Hospital [NWH], and the police - as places women could turn to for help with IPV than family, friends, or the church. As a client remarked, "Women tend to open up to strangers, like doctors, compared to relatives and friends when it comes to domestic violence" (Client, ANC). It is likely, then, that fear of retribution, stemming from a lack of confidentiality, may figure prominently in women's calculus on where to seek help.

\begin{tabular}{|l|c|c|c|c|c|c|c|c|c|c|}
\hline \multicolumn{1}{|l|}{ Table 4: Places cited by clients where IPV survivors can go for help } \\
\hline & FIDA & NWH & Police & $\begin{array}{c}\text { KNH/ } \\
\text { GBVRC }\end{array}$ & $\begin{array}{c}\text { Local } \\
\text { Admin. }\end{array}$ & Friends & Church & $\begin{array}{c}\text { KNH/ } \\
\text { CCC }\end{array}$ & Family & Other \\
\hline ANC & 4 & 5 & 1 & 1 & 1 & 1 & 1 & 0 & 0 & 1 \\
\hline CCC & 6 & 4 & 5 & 0 & 3 & 2 & 3 & 2 & 0 & 3 \\
\hline GBVRC & 1 & 2 & 3 & 4 & 2 & 1 & 0 & 0 & 0 & 1 \\
\hline Youth Centre & 6 & 6 & 5 & 4 & 2 & 2 & 1 & 0 & 1 & 3 \\
\hline Totals & 17 & 17 & 14 & $\mathbf{9}$ & $\mathbf{8}$ & $\mathbf{6}$ & $\mathbf{5}$ & $\mathbf{2}$ & $\mathbf{1}$ & $\mathbf{8}$ \\
\hline
\end{tabular}

Notably, the top three places cited by clients all have a history of receiving focused media attention in Kenya when it comes to incidents of violence. Awareness of the GBVRC at Kenyatta National Hospital was comparatively low, indicating a need for increased advocacy both internally within the hospital grounds, as well as externally among the general public. When asked if they knew of any places that survivors of violence could go to for help, respondents that mentioned $\mathrm{KNH}$ often did so in the following manner:

I think here at KNH, but I don't know the department (Client, Youth Centre).

Any hospital - even here at KNH (Client, ANC).

I don't know of any place, but since you have told me about this place here at KNH [GBVRC], I can tell my friends about it (Client, Youth Centre).

\section{Perceived facilitators for IPV referral compliance}

Client follow-through with IPV referrals is an important area for understanding the extent of IPV screening acceptability, as the screening process is closely linked to referral for IPV services. Once clients are sufficiently empowered to approach a provider, the importance of effective referrals is also essential in order to diminish long-term health care costs both to the client and the health system. A 2010 study in Kenya has definitively shown the long-term cost benefits of having efficient services for the care and treatment of violence ${ }^{22}$.

Understanding of client follow-through on referrals has tended to focus on external motivation factors, such as provider characteristics, financial incentives, or referral coordination

\footnotetext{
22 Division of Reproductive Health, Ministry of Health, Kenya (2010). Costing Post Rape Care Services in the Public Health Sector in Kenya. Undertaken in partnership with: Liverpool VCT, Care and Treatment Kenya Health Policy Initiative.
} 
improvement. ${ }^{23}$ Findings from this study, however, highlight the importance of both external and internal factors as motivators for clients to follow through on IPV referrals. Clients' ability to act - both perceived and real - can be viewed as an important indicator of program acceptability.

\section{External motivation factors}

\section{Perceived benefits}

Some clients conceptualized help for IPV in the form of non-medical responses, assuming that following through with IPV referrals might accrue benefits to survivors, ranging from rapid legal assistance, to marriage counseling, and financial assistance:

[Some] will think that women will be given money for food or school fees, or get benefits like ... money for business (Client, ANC).

I can also get help because of what I'm going through ... in my marriage. ... Maybe you are setting up small businesses for women who are being abused and I can be helped through that (Client, CCC).

It will help give women advice which will help them to reform their behavior so that they can stop annoying their husbands and this will make marriages strong (Client, Youth Centre).

Expectations, such as those mentioned by clients above, are associated with potential risks. Although the GBVRC indeed represents one kind of one-stop centre model ${ }^{24}$ (providing psychosocial and some medical services, and linking clients to other medical services within $\mathrm{KNH}$, as well as to external police and legal, and social services), it is important to consider how these linkages, when weak, might reflect on the GBVRC as a site that clients would want to obtain services from. The fact that the police and criminal-justice components of a multi-sectoral response to sexual and gender-based violence require strengthening is commonly acknowledged. ${ }^{25}$ Respondents from the GBVRC reflect below on some of their experiences with the legal and police linkages provided within this one-stop centre:

I think [those] ... who have been given the responsibility of legal matters are not doing their work in helping women with these problems. ... they have never represented me in court. I am always alone in the courtroom .... Sometimes I regret having taken this case to this place (Client, GBVRC).

We write PCR forms [for the police] and some of them don't go for the referral. One client said, 'They [the police] told me to stop embarrassing my husband and go back and sort things out.' Sometimes, the [survivor's] husband has already bribed the chief, so there's nothing you can do (Provider, GBVRC).

\footnotetext{
23 See, for example, Akbari A., Mayhew A., Al-Alawi MA, Grimshaw J, Winkens R, Glidewell E, Pritchard C, Thomas R, \& Fraser C. (2008). Interventions to improve outpatient referrals from primary care to secondary care. Cochrane Database Syst Rev. 8 (4):CD005471; Hysong SJ, Esquivel A, Sittig DF, Paul LA, Espadas D, Singh S, \& Singh H (2011). Towards successful coordination of electronic health record based-referrals: A qualitative analysis. Implementation Science 6 (84) doi: 10.1186/1748-5908-6-84; Gagnon A, Carnevale F, Saucier J, Clausen C, Jeannotte J, \& Oxman-Martinez J (2010). Do Referrals Work? Responses of Childbearing Newcomers to Referrals for Care. Journal of Immigrant and Minority Health 12(4): 559-568.

${ }^{24}$ For a discussion of other possible models, see, for example, Keesbury \& Askew (2009). Lessons learned in providing SGBV services in Africa. Presentation given at the 2009 SVRI Forum (http://svriforum2009.svri.org/presentations/Keesbury.pdf)

25 See, for example, Population Council, SIDA, \& ICRH (2009). Sexual and Gender-Based Violence: First Annual Coast Policy Conference. Report on Conference Proceedings < http://www.svri.org/coastpolicy.pdf $>$.
} 


\section{Actual benefits}

Given the weak links in the system, it was evident that clients need and want a clearer understanding of the actual benefits available to survivors. This emerges as an important factor that could potentially motivate survivors to follow through with IPV referrals. Clarity about what a survivor can expect to gain from referral follow-through was overwhelmingly emphasized by respondents.

The [provider] needs to really explain the kind of help which is available so [survivors] can understand the benefit of going where they are being told to go (Client, ANC).

Emphasize to [survivors] the benefits and help that they are going to get if they go (Client, Youth Centre).

You can use adverts or radio to tell women about the help which is available here, so when they are referred here, they will have an idea of the kind of help they can get (Client, GBVRC).

\section{Provider respect and distance}

One theme that emerged as an external influence and that could help ensure greater referral compliance was provider respect and distance. Clients perceived that the involvement of providers (particularly - but not solely - doctors) in the referral process would serve to greatly enhance the chances of survivors complying with referrals for IPV. Providers in hospital settings were seen by respondents as highly respected due to their specialized training, and their recommendation that a survivor access further services was viewed as persuasive:

You can use doctors to convince [survivors] to come [for IPV services]. Patients really respect doctors and they will listen to them (Client, GBVRC).

The doctor means everything to me. I believe that he can help me, so I would open up to bim. I look up to the doctor and have confidence ... that if he says he wants to belp me ..., he will help me (Client, CCC).

In addition to provider respect, the professional distance typically maintained by providers was also considered as critically important for ensuring that survivors feel safe to disclose IPV experiences. Confidentiality was considered crucial and acquaintances were deemed less likely to be able to maintain this:

[A survivor] can tell the doctor or nurse and [they] will not gossip about her because they are strangers
(Client, $A N C)$.

The doctor is a stranger and talking to a stranger is not like talking to someone you know, who might tell everyone (Client, CCC).

\section{Internal motivation factors}

Respondents placed considerable emphasis on internal motivation factors, which again brings the issue of agency — or a survivor's ability to act upon her needs - to the fore where care, treatment, and (in the long run), prevention of violence are concerned.

\section{Catharsis}

Overwhelmingly, the perceived cathartic effect expected from a successful IPV referral and follow-through was highlighted by respondents as a factor that could help ensure IPV referral compliance. IPV referral compliance was viewed by participants as a rare entry-point into a space explicitly designed for survivors to have their voices heard without fearing breaches of confidentiality. This prospect was overwhelmingly viewed as sufficient to motivate any survivor to follow through with referral for further care: 
I know many women will not refuse ... because most women experience IPV, but they may have never had an opportunity of someone asking them about it in a bospital set-up (Client, ANC).

In most cases, women are never given a chance to talk. Many are harassed sexually but society has no avenues to make them talk. This will be a chance for them to do so (Client, Youth Centre).

They will be willing. We don't have many other alternative places we can go to talk about such things (Client, GBVRC).

$[W]$ omen have many problems and they are just waiting for an opportunity for someone they can share with so as to release the stress they have been carrying (Client, CCC).

\section{Women as agents of social change}

Another major feature of respondents' narratives had to do with women seeing themselves as potential agents of social change where IPV is concerned. This collective spirit and action is welldocumented in the literature on reproduction. ${ }^{26}$ Respondents strongly perceived that women (survivors and non-survivors alike) would be likely to help others by sharing information on where to get help for violence. The screening process was thus seen as an educative one, in that whether one was experiencing violence or not, it would inadvertently create awareness around IPV as a problem, and notably around where assistance and services might be obtained. Women also repeatedly emphasized the desire to share information gained through the IPV screening process with their peers, and referred to the screening process as providing information which could be useful to them personally in the future, if not at the actual time of IPV screening:

Even if I'm not experiencing violence right now, those services will help other women, and some of them could be my friends. And if you know about these services, you can tell other women who may not know about it (Client, $A N C$ ).

You never know about life. I may go through it in [the] future and I'll be able to know where to go for help. I can also tell my friends about it and they will be able to get help before something serious happens to them (Client, Youth Centre).

Women who will have been identified can go out there and share this idea with their friends and relatives. ... [S]ometimes they don't know where go get help... You know, I did not know about this place [GBVRC] ... had I known, maybe this would have been the first place for me to go (Client, GBVRC).

\section{Hidden demand for IPV services}

The sheer desire for assistance as a catalyst toward IPV referral compliance emerged as a recurrent theme among respondents. Here, women highlighted the fact that IPV screening holds potential for capturing those survivors that represent 'low hanging fruit', in the sense that they are ready for intervention and require no coaxing beyond the provision of information about the availability of services:

If a woman is suffering because of her husband and she wants to be helped, she will go because she wants somebody to help her (Client, ANC).

If she wants to be helped, if she wants a breather in her life from what she has been going through, then she will go (Client, Youth Centre).

Mainly, because they are fed up with their situation and don't know what to do next, they will go, hoping that someone will be able to help them before they go mad (Client, CCC).

\footnotetext{
${ }^{26}$ Ginsburg, F.D. \& Rapp, R. (eds.) 1995. Conceiving the New World Order: The Global Politics of Reproduction. University of California Press.
} 
Like me, I had been suffering for 4 years since my husband started beating me. I didn't know what to do or where to go. But a friend of mine told me about this place and I decided to come because she told me I could get help. I came because I needed help (Client, GBVRC).

\section{IPV Screening: What do Women Want?}

All 68 clients interviewed perceived routine screening for IPV to be an important and useful exercise. Nonetheless, respondents also articulated a number of desirable conditions without which women's participation in IPV screening processes and client follow-through with referrals might, in fact, be hampered. As the quotations to follow demonstrate, the desirable conditions articulated by women fell into six main themes, namely: confidentiality, positive provider attitudes, convenience, respect for choice, de-stigmatized spaces for care, and preferred provider characteristics.

\section{Confidentiality}

Privacy was a major concern of respondents, who wanted to be sure that the strictest of confidentiality would be observed by providers involved in the screening process: "Reassure [survivors] that whatever they talk about will be kept confidential, and other people like their relatives or [partner] will not find out she was talking about bim" (Client, ANC).

\section{Positive provider attitudes}

As to be expected, the attitude of providers toward survivors was also considered by participants to pose a major threat to both IPV screening and IPV referral compliance. One client, for instance, likened survivors to customers that respond positively to good customer service: "If the provider is rude, [survivors] won't go. It's just like going to a shop on the first day and you talk to me badly. Of course, I'm not going to come back"' (Client, ANC).

\section{Convenience}

The more convenient the referral process is made for women, the more likely they would be to attempt to access IPV services, according to those interviewed. Convenience was defined by clients in regard to proximity of the IPV services ("They should be referred to a room which is nearby so they don't have to move out of the Youth Centre" - Client, Youth Centre), cost ("Offer the services and the help free of charge" Client, ANC), and speed ("[O]ffer them the services that they came for as quickly as possible so that they don't have to wait for long [at the point of screening], and they will have the time to come here [the GBVRC]" - Client, GBVRC).

\section{Respect for choice}

Although only expressed by a minority of respondents (four in the Youth Centre and one in the GBVRC), the need for choice in the screening and referral follow-through process merits attention. All respondents were asked how they would have reacted towards being asked IPV screening questions were such questions to have been posed during their current hospital visit. Five respondents, the majority of whom were young people from the Youth Centre, had reservations about being screened for a condition unrelated to the original purpose of their hospital visit. Although this did not emerge as a major theme, patients' rights play an important role in any work around violence:

I did not come here today prepared to answer such questions. I only came ... for VCT and I don't want to waste time answering unnecessary questions. I only agreed to talk, to you because you asked me nicely (Client, Youth Centre). 
I think when I have come for ANC services [for instance], I may not be prepared psychologically to talk about [IPV]. At that time, my main aim is to get ANC services and leave. ... I wouldn't discuss my busband and expose unless I'm going through counseling (Client, GBVRC).

It is noteworthy, however, that, as indicated by the first quote above, even the most reticent of clients can be persuaded by positive provider attitudes. Ensuring willingness, as with any consenting process, enhances a survivor's sense of safety and will likewise enhance providerclient rapport.

Another element of choice that emerged from interviews with clients had to do with the right of survivors to choose to remain with an abusive partner, despite the possible health, social, and other consequences of doing so:

When I tell you my problem, don't start telling me that I need to leave my boyfriend. If you give me such advice, I will not go [for IPV services] (Client, Youth Centre).

I want to be able to tell you about my problem, but don't listen and then start saying bad things about my husband, or telling me to leave bim. Just advise me on what else I can do, but [don't] destroy my marriage (Client, $A N C$ ).

\section{De-stigmatized spaces for care}

The GBVRC is currently housed within the Patient Support Centre, which is also home to KNH's Psychiatry Department. The Patient Support Centre provides various kinds of support to several categories of clients (e.g., mental health clients, substance abuse clients, and HIV-positive clients). The Centre also provides multi-sectoral linkages and support to survivors of genderbased violence. This impressive effort, however, comes with an unintended consequence - the fear of increased stigma. A few, though not insignificant number of, GBVRC clients, felt that the fear of stigma (i.e., the stigma of seeking services at the GBVRC) could serve as a deterrent to accessing services for some survivors:

Stigma.... It took me a lot of courage before I finally came. When people see you on these benches [in the waiting area], they will say you are one of those women who are normally beaten, or: People who come here are the ones that want to break their homes by reporting their husbands' (Client, GBVRC).

I would say stigma because some people already associate this place with people that have either been raped, assaulted physically, or are suffering from HIV / AIDS, and therefore may feel uncomfortable coming here (Client, GBVRC).

Although this opinion was only expressed by GBVRC clients, and by only two out of the eight clients interviewed in this site, it is noteworthy, given the possible implications for referral follow-through and given the fact that violence remains highly stigmatized throughout Kenyan society. Resolving this issue - stigma related to the Patient Support Centre-is critical, as many women experiencing violence suffer as well (as the reader will learn) from underlying chronic health and behavioral conditions such as substance abuse, mental health problems and HIV/AIDS. 


\section{Preferred provider characteristics}

To gain an understanding of the kind of provider with whom clients would feel most comfortable performing an IPV screening role, respondents were asked specific questions about their preferences around provider type, age, and gender. Counselors were overwhelmingly preferred by respondents given that their training was perceived as having prepared them most adequately for this role:

A counselor will be better at creating a good rapport and relationship with me since they bave been trained in that (Client, $A N C$ ).

I would prefer a counselor. A doctor deals with treatment. A counselor has already counseled many other people and has been able to lift them out of depression and he will be able to life me up as well because of [bis] experience (Client, CCC).

Table 5 below describes the number of times counselors were mentioned by clients as the preferred provider for conducting IPV screening. The preference for counselors may also be explained by the fact that, when talking about their preferred provider, most respondents had the actual provision of IPV psycho-social services in mind, rather than the screening process alone, which involves a provider asking the client a few, short questions.

\begin{tabular}{|l|c|c|c|c|}
\hline \multicolumn{1}{|l|}{ Table 5: Clients' preferred provider for conducting IPV screening } \\
\hline & Counselor & Doctor & Nurse & $\begin{array}{c}\text { Doesn't matter } \\
\text { as long as trained }\end{array}$ \\
\hline ANC & 10 & 2 & 1 & 6 \\
\hline CCC & 17 & 2 & 0 & 2 \\
\hline GBVRC & 7 & 0 & 1 & 0 \\
\hline Youth Centre & 15 & 4 & 0 & 3 \\
\hline Total & $\mathbf{4 9}$ & $\mathbf{8}$ & $\mathbf{2}$ & $\mathbf{1 1}$ \\
\hline Multiple responses were allowed \\
\hline
\end{tabular}

Provider age did not emerge as a major issue of concern for respondents, apart from among Youth Centre clients (5 out of 20 ). For the vast majority of clients, the age of the provider performing a screening or IPV counseling role was not nearly as important as the maturity displayed by the provider concerned. The following represents the typical response of participants to the question of what age they would prefer providers to be:

Does age really matter? You just need to be mature enough. How you approach me is what matters. Like you now, you look young, and I am 50, but we are talking nicely because you approached me with respect and explained what you wanted (Client, CCC).

Concerns about providers performing the IPV screening role being too old were expressed by a minority of respondents in the Youth Centre, however:

I wouldn't feel comfortable talking to someone as old as my [parent]. I will not answer some questions honestly because I will feel like it's my [parent] asking and I can't talk to them about such things (Client, Youth Centre).

It is easier to talk, to a youth than an adult. [Talking to] an adult is just like talking to my mum and I won't be able to reveal some secrets to her (Client, Youth Centre).

Provider gender was not highlighted as a critical issue for most respondents. The words of an ANC client reflect the sentiments of the vast majority of those interviewed: "When it comes to gender, I really don't care; any [gender] can do, so long as it is someone experienced." 


\section{IPV Screening: Convergences between client and provider priorities}

There were two important convergences around what clients ideally wanted their potential IPV screening experiences to be like, and what providers felt was actually possible. Firstly, providers, like clients, were of the opinion that counselors should ideally attend to the psycho-social needs of IPV survivors. Secondly, providers shared clients' concerns about ensuring a convenient IPV referral process.

Like clients, providers regarded counselors as being well-placed to handle the task of IPV screening and the psycho-social support that follows screening:

GBVRC counselors can address them [IPV clients]. Refer them here (Provider, GBVRC).

With more counselors (we as clinicians now realize the importance of having counselors) [IPV screening] should be done; and with counseling, the quality of our services would improve across the board (Provider, $A N C)$.

Providers outlined two primary areas of concern around the referral process which were also highlighted by clients: proximity and speed. The sheer size of Kenyatta National Hospital (a facility with a staff capacity of 6,000 and nearly 40 Departments ${ }^{27}$ ) was noted as posing a navigation challenge for even regular clients. Secondly, moving toward (physical) one-stop centre models for providing IPV services was a desire expressed by providers both within and beyond the GBVRC, as a way of keeping the referral process as convenient as possible for clients. In the absence of such models, other solutions were proposed, however:

I think. when it's a one-stop shop, it's easier because everything is handled in the same place.... The GBVRC is not a one-stop shop because we don't have a doctor here, so when the patient comes, we take the bistory, then refer to [the] Casualty [department] if they need a physical check-up, then back to the GBVRC for counseling. So, it's a whole rotation (Provider, GBVRC).

I'm a believer in integration. I'm a believer in one-stop shops. There should be a counselor right there lat the ANC]. Why should you refer them elsewhere? They've come, they're pregnant. They didn't come for GBV stuff. I also treat HIV patients right here, so why not other things? If we must use referrals, this should be effective - for example, having patient escorts that can band the patient over to the next provider. If you must use referral slips, make sure they're evaluated monthly to ensure things are working well. And this place [Kenyatta National Hospital] is huge, so the referral point shouldn't be far away (Provider, ANC).

Another priority of providers in regard to the IPV screening process that aligned with the concern of clients had to do with the speed of the IPV referral process. As a provider pointed out:

Maybe they [the client(s)] have spent the whole day here; they're leaving at 3:00 pm, then you're telling someone to go to the $[G B V R C][$.$] Someone should make sure they are booked, and so on ... [There should$ be] someone specifically assigned to pick up patients, and a way of identifying this unique patient so they don't have to wait all over again [at the GBVRC] (Provider, CCC).

The concern expressed by the provider above is a valid one, given the findings from the client flow analysis discussed previously (see Table 2). However, as explained by a GBVRC provider:

\footnotetext{
${ }^{27}$ Mars Group (2007). The Kenyatta National Hospital. < http://www.marsgroupkenya.org/pdfs/Oct 07/Parastatals/Kenyatta National Hospital/THE KENYATTA N ATIONAL HOSPITAL Mandate.pdf $>$.
} 
We give [survivors] first priority, even if other clients are waiting. And you don't hand [the survivor] over. You walk with that person to the end ... up to [the] Casualty [department], to the OB/GYN room ... and hand [the survivor] over to someone who understands [the survivor] is not to be delayed (Provider, GBVRC).

Concern for IPV survivors' well-being while within the hospital setting was evident across the provider interviews, and was clearly an issue for clients themselves. The lack of a structure and standards for facilitating this process was also apparent. Compassionate referrals and care for GBV survivors, for instance, are occurring at Kenyatta National Hospital, as exemplified by the quote above. But these referrals for survivors are not conducted systemically; rather, IPV detection is more serendipitous, depending on a host of conditions, at $\mathrm{KNH}$ :

If [providers] realize it's GBV ..., they will just send you there [to the GBVRC]... The screening is not systematic. You're the one [as the survivor] to tell them what happened (Provider, GBVRC).

We have a certain department that deals with that and it's our Patient Support Centre [GBVRC]. So, normally, we refer [survivors] there for counseling and action. We give them a referral slip. But women often don't go (Provider, $A N C$ ).

In addition to systematic screening procedures, adding human resources, in the form of escorts, could be an innovative way to ensure referrals and possibly follow-through. While staff shortages are often cited, there are a host of potential workers-in-training, including psychologists, counselors, nursing students, social workers, and others who could assist with the escorting process which would in turn build awareness and capacity within the health system.

\section{Overview of client and provider perspectives on screening}

All clients interviewed were amenable to the idea of integrating routine screening for intimate partner violence into other health care services. The important concerns of some clients around the introduction of IPV screening have been discussed. These concerns notwithstanding, the idea of routine screening for IPV was favorably viewed and unanimously received by women. One respondent with a keen understanding of the benefits of IPV screening, having received care from the GBVRC herself, made the following poignant comment:

I think it's a very important move. If I had someone who had asked me such questions, then I wouldn't have suffered for that long like I did. I used to come here $[\mathrm{KNH}]$ all the time for treatment, but nobody ever asked me anything. I would come here for treatment after my husband had beaten me. I'd be treated and then I'd be told to go home. Sometimes, my husband used to box me in the head; and so, some women [have] injuries in the head but they have no physical symptoms to show that (Client, GBVRC).

Some providers acknowledged staff shortages as a concern that could have implications for effective IPV screening. Nonetheless, routine IPV screening was viewed by all providers as a welcome initiative overall, firstly because they perceived such an initiative as having the potential to positively affect a large number of women and youth, but also because of the apparent association between violence and a host of other mental and physical health problems:

It's a good idea and would go a long way toward helping women at large. ... [G]iven an opportunity, triggering it through a question, you'll definitely get a response from quite a large proportion (Provider, Youth Centre).

It's something I've been thinking about ... I think [IPV screening] needs to be incorporated. Because I feel that sometimes, IPV may be responsible for some of these conditions we treat: HIV, substance abuse, depression, etc. And you bave to screen because people won't come to tell you that 'I'm a victim' (Provider, GBVRC). 
We're very few already staff-wise, but that's the case for the whole hospital. It may be overwhelming in one way or the other, but it will have a positive impact overall. Because if we start to do something about this issue, it will reduce the number of psychiatric patients we have over here, or the number of substance abuse patients we have, and so on. So rather than stay blindly because we fear the increased numbers, let's do something (Provider, GBVRC).

\section{Provider recommendations for other IPV screening points}

Providers were asked for their opinions on other departments at $\mathrm{KNH}$ that would be ideal for the introduction of IPV screening. Their responses were based on the perception that detection of IPV survivors in the mentioned locations would be high, or simply that the mentioned locations typically drew together large numbers of women and youth. Nearly half of these proposed screening contact points (Casualty, Burns Centre, Youth Centre, CCC, and Pediatric Surgery), include the likelihood of capturing youth and children, who are also increasingly survivors of emotional, physical and sexual violence, according to national data. Table 6 indicates the departments mentioned by providers and the number of times they were mentioned by individual providers.

\begin{tabular}{|l|c|}
\hline \multicolumn{1}{|c|}{ Table 6: Provider recommendations for other IPV screening points } \\
\hline \multicolumn{1}{|c|}{$\begin{array}{c}\text { Gynecological Wards } \\
\text { (including acute GYN ward, labor and } \\
\text { delivery ward, post-natal care ward, } \\
\text { ANC) }\end{array}$} & $\begin{array}{c}\text { Number of times mentioned } \\
\text { by different providers }\end{array}$ \\
\hline Family planning clinic & 4 \\
\hline Accident \& Emergency ('Casualty') & 4 \\
\hline $\begin{array}{l}\text { Patient Support Centre/Psychiatric } \\
\text { Clinic/GBVRC }\end{array}$ & 3 \\
\hline Burns Centre & 2 \\
\hline Surgical wards & 2 \\
\hline Youth Centre & 2 \\
\hline Adult ward & 1 \\
\hline CCC & 1 \\
\hline Pediatric surgery & 1 \\
\hline Multiple responses were allowed & \\
\hline
\end{tabular}

\section{Summary of Findings}

Although routine screening for intimate partner violence is a current recommendation of several professional associations in industrialized countries, developing country contexts such as Kenya have yet to take on this task. There are good reasons for this hesitation, given that strong health systems should ideally be in place prior to the introduction of IPV screening. The current proliferation of one-stop GBV centers on the continent, however, now provides an opportunity to determine the acceptability of routine IPV screening. That violence has become an increasingly serious public health concern in the region emphasizes further the need for acceptability assessments around this issue. As most research on IPV screening has been conducted in developed countries, this study serves as one of the first in a developing country context to have assessed the acceptability of IPV screening from the perspective of providers and clients in public health care settings — and the results are decidedly encouraging.

In summary findings from the study indicate the following:

1. There is considerable concurrence between providers and clients on the importance and relevance of screening and referrals for the care and treatment of violence. In fact, the single area of disconnect between providers and clients lies in the definition of IPV. Providers tended to cast IPV into the realm of sexual violence, while clients and survivors included the physical, economic, and emotional/psychological aspects of IPV 
as relevant, if not more common than sexual violence. This challenge could be easily remedied through trainings and raising advocacy generally around all aspects of violence and the services available in response.

2. IPV is perceived by clients and providers as being a highly prevalent issue in the lives of Kenyan women, with providers in particular estimating that it is a lived experience of anywhere from a third to over half of their clients.

3. Despite perceptions that IPV is extremely prevalent in the lives of women, few clients (some of whom were also hospital staff) are aware of the existence of the Gender-Based Violence Recovery Centre at Kenyatta National Hospital. Yet, clients perceive that survivors of IPV are more likely to seek assistance in hospital settings than with family or friends.

4. Although compliance with referrals among clients is often linked to external factors that prompt and encourage follow-through, the study found that there are also important (and usually overlooked) internal factors that could serve to ensure improved IPV referral compliance.

5. All providers and clients interviewed were of the opinion that screening for IPV is an important and useful undertaking that would be highly beneficial to women. Given the perceived importance of the issue, providers also gave recommendations for other departments within Kenyatta National Hospital where screening is needed, considering the estimated large number of IPV cases that are likely present in these settings.

\section{Conclusion and Recommendations}

In conclusion, routine screening for IPV is acceptable to providers and clients at Kenyatta National Hospital, provided that the system as it currently stands is reinforced in specific ways (e.g., assurance of confidentiality, positive provider attitudes, and respect for patient rights). These conditions largely fall within the expected norm when it comes to the quality of care provided within accredited health facilities.

The major recommendations from the study include: improved awareness-raising around definitions of violence and available services; improved quality of care; and the provision of child- and youth-friendly services.

1. Improved awareness-raising around definitions of violence and available services As most $\mathrm{KNH}$ clients were unaware of the existence and/or the mandate of the GBVRC, mechanisms must be found to publicize the GBVRC, both within and beyond Kenyatta National Hospital. Awareness-raising, if done properly, becomes an integral part of future prevention work, alerting would-be perpetrators that an effective response system is in place. Speaking about violence openly will also serve to de-stigmatize the issue in public forums.

While awareness is being raised, improved training among health care providers on the screening process (including sensitization on GBV and IPV, positive provider attitudes, and non-coercive messaging about unhealthy relationships) is essential and should occur before the introduction of IPV screening and continue on a regular basis thereafter. Once IPV screening is introduced, it should, to the extent possible, be integrated into the normal medical history-taking process, serving to further de-stigmatize the screening procedure. Training sessions should move providers towards more realistic and holistic 
definitions of IPV that resonate with their client population, while also providing a better understanding of what services clients can expect to receive at the GBVRC.

Related to this, it is important for the GBVRC to take stock of its primary strengths as a one-stop centre and to highlight the components of the GBV response model that are working well during the provider trainings. This will help providers to convey clear messages to IPV survivors on the kind of help they can realistically expect as a result of referral. The training of 'escorts' to attend to survivors as they move through the system would also be beneficial. This training could be geared towards allied health staff who have not yet completed their training but are still required to spend time in the work setting, thus serving to prepare future cadres of health care workers with a more holistic understanding of violence care and treatment.

2. Improved quality of care

Quality of care is essential to the success of any medical intervention. Patient flow and costing are two elements of the quality of care framework that can define a client's experience in the health care setting ${ }^{28}$. Given the lengthy waiting times that clients experience in various departments (and client and provider desires for the referral process to be convenient), there is a need to standardize existing, compassionate referral processes at $\mathrm{KNH}$, moving them from an ad hoc basis to a standard procedure between the GBVRC and other departments.

\section{Provision of child-and youth-friendly services}

Finally, given that a substantial proportion of survivors of violence in Kenya are children and youth, efforts should be made to improve the quality of care available within childand youth-friendly services provided to Kenya's younger cohort. Young people in this study (interviewed at the Youth Centre) emerged as a special group with slightly different needs from clients interviewed in other departments. Their main concerns revolved around the need for the IPV screening process to be youth-friendly. The recommendation is for the GBVRC and the Youth Centre to work closely together in meeting the needs of young IPV survivors.

Based on the results of this acceptability study, an IPV screening tool was developed in October 2011 by the Kenyatta National Hospital's IPV Taskforce in collaboration with the Population Council. This tool will be piloted in 2012, through a partnership between the Population Council and Kenyatta National Hospital, to assess the feasibility of administering it routinely in public health care settings to fully measure the success of the IPV screening program - the first of its kind on the African continent.

\footnotetext{
${ }^{28}$ Bruce, J. 1990. Fundamental elements of the quality of care: A simple framework. Studies in Family Planning 21(2): 61-91.
} 


\section{Appendices}

\section{Appendix A: IPV Screening Tool}

\section{Intimate Partner Violence (IPV) Screening Tool}

The prevalence of intimate partner violence is sufficiently high, and its ongoing character is such that providers in settings such as ANC, CCC, GBVRC, and Youth Centre settings will encounter survivors on a regular basis. Persons in clinical settings are more likely to have experienced intimate partner violence than non-clinical populations. ANC, CCC, GBVRC, and Youth Centre settings therefore offer an opportunity to screen women who present for routine health maintenance and those who have specific health complaints.

\section{Who will be routinely screened for intimate partner violence under this pilot program?}

All female clients that seek services within the ANC, CCC, GBVRC, and Youth Centre at Kenyatta National Hospital (KNH).

\section{What should clients be screened for?}

At every visit, female clients should be screened for any intimate partner violence that occurred anytime in their lives, over the past year, or that is occurring presently.

\section{When should screening occur?}

Routinely, at every visit to the ANC, CCC, GBVRC, and Youth Centre, and as part of the normal medical history-taking process.

Intimate Partner Violence screening will be conducted by making the following statement and asking these 4-5 questions:

\section{Antenatal Care Centre}

"Many people do not realize that violence can lead to all kinds of health problems. Because violence is so common in many women's lives, and because there is help available at $\mathrm{KNH}$ for women being abused, we now ask all patients in the ANC about their experiences with violence:

1. Within the past 12 months - or since you have been pregnant - have you been hit, slapped, kicked, or physically hurt in anyway by someone?

2. Are you in a relationship with a person who physically hurts you?

3. Are you in a relationship with a person who threatens, frightens, or insults you, or treats you badly?

4. Are you in a relationship with a person who forces you to participate in sexual activities that make you feel uncomfortable?

\section{Comprehensive Care Centre}

"Many people do not realize that violence can lead to all kinds of health problems. Because violence is so common in many women's lives, and because there is help available at $\mathrm{KNH}$ for women being abused, we now ask all female patients in the CCC about their experiences with violence:

1. Within the past 12 months, have you been hit, slapped, kicked, or physically hurt in anyway by someone?

2. Are you in a relationship with a person who physically hurts you?

3. Are you in a relationship with a person who threatens, frightens, or insults you, or treats you badly?

4. Are you in a relationship with a person who forces you to participate in sexual activities that make you feel uncomfortable?

\section{Youth Centre}

"Many people do not realize that violence can lead to all kinds of health problems. Because violence is so common in many women's lives, and because there is help available at KNH for women being abused, we now ask all female patients in the Youth Centre about their experiences with violence:

1. Within the past 12 months, have you been hit, slapped, kicked, or physically hurt in anyway by someone?

2. Are you in a relationship with a person who physically hurts you? 
3. Are you in a relationship with a person who threatens, frightens, or insults you, or treats you badly?

4. Are you in a relationship with a person who forces you to participate in sexual activities that make you feel uncomfortable?

\section{Gender-Based Violence Recovery Centre}

"Many people do not realize that violence can lead to all kinds of health problems. Because violence is so common in many women's lives, and because there is help available at $\mathrm{KNH}$ for women being abused, we now ask all female patients in the GBVRC about their experiences with violence:

1. Within the past 12 months, have you been hit, slapped, kicked, or physically hurt in anyway by someone?

2. Are you in a relationship with a person who physically hurts you?

3. Are you in a relationship with a person who threatens, frightens, or insults you, or treats you badly?

4. Are you in a relationship with a person who forces you to participate in sexual activities that make you feel uncomfortable?

5. At any point in your life, has anyone ever forced you to participate in sexual activities that made you feel uncomfortable? If 'yes,' at which point in your life did this occur?"

Childhood

Teenage years

Other [specify]

With disclosure of ongoing IPV, the provider's responsibilities include:

$\circ$ Acknowledgement of abuse

- Documentation

- Providing referral to the Gender-Based Violence Recovery Centre at KNH

- Follow up (at patient's next visit)

Adapted from:

1. The National Consensus Guidelines on Identifying and Responding to Domestic Violence Victimization in Health Care Settings. The Family Violence Prevention Fund. September 2002. (www.endabuse.org)

2. Recommendations by stakeholders at the Program Dialogue on Screening for IPV in Public Health Care Settings in Kenya, Intercontinental Hotel, Nairobi, September 8, 2011. 


\title{
Appendix B: Study Tools
}

\section{Client Exit Interview Guide (General)}

\section{Assessing the Acceptability and Feasibility of Screening for Intimate Partner Violence (IPV) in Public Health Care Settings in Kenya Population Council}

\author{
To be administered to clients exiting from ANC, CCC, and Youth Centre ONLY
}

Hello. My name is [Name]. I'm working on a project that KNH is conducting with the Population Council to try and ensure that women who are experiencing IPV are able to get the health care and help that they need. As part of this project, we are approaching up to 80 women that have received services at this hospital to ask some questions that will help us develop a plan for $\mathrm{KNH}$ and other hospitals to start helping women that have experienced IPV. You do not have to have experienced violence yourself in order to participate in a brief, confidential interview with me - we just want to gather the opinions of a wide variety of women on this subject.

If you agree to speak with me, I will take about 20 minutes of your time, asking what you know about intimate partner violence, what services you're aware of to help women that are experiencing this, and what you think about having $\mathrm{KNH}$ try to screen their patients to find out who might be undergoing this so they can be referred to other departments for help. Everything we talk about will be totally confidential. Your name will not appear on any of our reports. I will be taking down notes as we speak to be sure I do not miss any of the important information you share with me. If at any point you would like to stop, or if there are any questions you would rather not answer, that is fine - just let me know. Is there anything you'd like to ask me at this point?

1. Do you know of anyone that is currently experiencing IPV?

- If yes, what kind of IPV?

- From what you've observed, how much would you say women in Kenya tend to experience IPV? Kindly elaborate.

2. IPV can seriously affect women's health. It can lead to HIV; it can lead to pregnancy loss; it can cause depression and lead to suicide, etc. Because of this, we're thinking about how we can help women that are in this situation before it's too late. One idea is to identify these women early by having a doctor/nurse privately ask every woman that comes to the [ANC/CCC/GBVRC/Youth Centre] whether they are experiencing IPV. If they are, then they would be referred to other departments at $\mathrm{KNH}$ where they can get the health care they need, and other services.

- How do you think women who come to KNH would react to this approach/idea?

- What do you like about this approach/idea? Dislike?

- Do you think women who come to $\mathrm{KNH}$ would be willing to answer a few questions (from a doctor/nurse) about their own experiences of IPV? Please elaborate.

- Would you have been willing to answer such questions if the doctor you saw today asked you some questions on IPV? Please elaborate.

- If KNH assigned someone to ask you such questions - like a doctor, nurse, or counselor - describe what type of person would be most helpful/what type of person you would be most comfortable with (age, gender, etc.)

3. Let's imagine that the person (doctor, nurse, etc.) finds women that are experiencing IPV and refers them for further services at $\mathrm{KNH}$. What would motivate women to go for this referral?

- What do you think is going to make it hard for women to go for this referral?

- What would help women overcome this problem (barrier)?

4. Do you know of any place where women who are experiencing IPV can get help?

- Name and location of place(s)

- What kind of help is offered at this place/these places?

- [If mentions only one type of help:] How useful would you say this kind of help might be to a woman experiencing IPV? Kindly elaborate. 
- [If mentions more than one type of help:] Out of the kinds of help that are offered by this place/these places, which would you say is the most useful to a woman experiencing IPV? Kindly elaborate.

\section{Interview Closing:}

I have asked a lot of questions of you. Now let me give you a chance to ask me questions. Do you have any question for me that is related to this project?

Thank you so much for your time. The information you have shared will be useful as we try to improve services for IPV at KNH. Kindly accept this directory of GBV services in Nairobi. We hope you, or those you know, will find it useful.

\section{Client Exit Interview Guide (GBVRC ONLY)}

\section{Assessing the Acceptability and Feasibility of Screening for Intimate Partner Violence (IPV) in Public Health Care Settings in Kenya Population Council}

\section{To be administered to clients that exited from the GBVRC ONLY}

Hello. My name is [Name]. I'm working on a project that KNH is conducting with the Population Council to try and ensure that women who are experiencing IPV are able to get the health care and help that they need. As part of this project, we are approaching up to 80 women that have received services at this hospital to ask some questions that will help us develop a plan for $\mathrm{KNH}$ and other hospitals to start helping women that have experienced IPV.

If you agree to speak with me, I will take about 15-20 minutes of your time, asking what services you're aware of to help women that are experiencing IPV, and what you think about having KNH try to screen their patients to find out who might be undergoing this so they can be referred to other departments for help. Everything we talk about will be totally confidential. Your name will not appear on any of our reports. I will be taking down notes as we speak to be sure I do not miss any of the important information you share with me. If at any point you would like to stop, or if there are any questions you would rather not answer, that is fine - just let me know. Is there anything you'd like to ask me at this point?

1. The health of a woman experiencing IPV can be affected. Because of this, we're thinking about how we can help women that are in this situation before it's too late. One idea is to identify these women early by having a doctor/nurse privately ask every woman that comes to the [ANC/CCC/GBVRC/Youth Centre] whether they are experiencing IPV. If they are, then they would be referred to other departments at $\mathrm{KNH}$ (such as the GBVRC) where they can get the health care they need, and other services.

- What do you think about this idea/approach?

- What do you like about it? Dislike about it?

- Do you think women who come to KNH would be willing to answer a few questions (from a doctor/nurse) about their own experiences of IPV? Please elaborate.

- If you came to KNH tomorrow for an antenatal care visit, for instance, how willing would you be to answer a few questions about any IPV experiences you may have had if asked by a doctor? Kindly elaborate.

- If KNH assigned someone to ask you such questions - like a doctor, nurse, or counselor describe what type of person would be most helpful/what type of person you would be most comfortable with (age, gender, etc.)

2. Let's imagine that a doctor, nurse, or counselor in the ANC clinic discovers women that are experiencing IPV and refers them to the GBVRC for further services. What would motivate these women to go for this referral?

- What do you think is going to make it hard for these women to go for this referral?

- What would help these women overcome this problem (barrier)? 
3. Do you know of any place where women who are experiencing IPV can get help?

- Name and location of place(s)

- What kind of help is offered at this place/these places?

- [If mentions only one type of help:] How useful would you say this kind of help might be to a woman experiencing IPV? Kindly elaborate.

- [If mentions more than one type of help:] Out of the kinds of help that are offered by this place/these places, which would you say is the most useful to a woman experiencing IPV? Kindly elaborate.

\section{Interview Closing:}

I have asked a lot of questions of you. Now let me give you a chance to ask me questions. Do you have any question for me that is related to this project?

Thank you so much for your time. The information you have shared will be useful as we try to improve services for IPV at KNH. Kindly accept this directory of GBV services in Nairobi. We hope you, or those you know, will find it useful.

\section{Provider Interview Guide}

\section{Assessing the Acceptability and Feasibility of Screening for Intimate Partner Violence (IPV) in Public Health Care Settings in Kenya Population Council}

Thank you so much for meeting with me today. My name is [Name]. I work with the Population Council on a project that aims to assess how acceptable and feasible it is to screen for IPV in public health care settings in Kenya, such as this one.

To help with this assessment, we are talking with several providers at Kenyatta National Hospital and Moi Referral Hospital to gain their perspective on how acceptable and feasible this endeavor might be. We've requested an interview with you because we believe that as a health provider in [Name of Department], you have probably had some dealings with clients experiencing IPV, and your experience and viewpoints would be useful in helping us understand the modalities for successfully screening for intimate partner violence. I would therefore like to ask you some questions around this very issue.

Before we start, I want to assure you that everything we talk about is confidential. Your name will not appear on any of our reports. I will be taking down notes as we speak to be sure I do not miss anything. If at any point you would like to stop, or if there are any questions you would rather not answer, just let me know. Is there anything you'd like to ask me at this point?

1. Perhaps we could start off by having you provide me with your own understanding of the term 'genderbased violence.' What does this term mean to you as a provider?

- What about 'intimate partner violence' - what is your understanding of this term- would you say it is the same, or would you say it differs from GBV, and if so, how?

- From what you've observed through your work at this hospital, how prevalent would you say GBV or IPV is? Kindly elaborate.

2. [If provider works in CCC]: In your work with HIV-positive individuals, what kind of relationship(s) have you observed, if at all, between GBV/IPV and HIV?

3. Are there any services offered at this hospital that you're aware of for clients that have experienced physical, emotional, or sexual violence? Kindly walk me through a description of each of them.

4. In situations where a client comes in to your department and reports that they have experienced/are experiencing physical, emotional, or sexual violence, what kind of protocols are in place at this hospital to ensure that such a person gets the help they need? 
5. Let's talk a little bit about routine screening. Are there any conditions you can think of that are routinely screened for in your department? Kindly give me an example.

- How exactly does routine screening for this condition occur?

- What do you think about the idea of incorporating routine screening for IPV into [Name of Department]?

i. How willing would you say you'd be to have this happen?

ii. How much capacity would you say there is within this department for this to happen successfully? Kindly elaborate.

iii. In your opinion, what might be the advantages and disadvantages of having such screening?

6. When you think about your department, the way it functions, and the various capacities it has, what other suggestions do you have for potential IPV screening points - i.e., places in the department that have been overlooked but that could actually be good spots for screening for IPV? Any other screening spots you can think of?

7. Based on your knowledge of this hospital's system, if you were asked to recommend how GBV/IPV clients should be referred from your department, what recommendations would you give to ensure the referral actually happens?

8. We've almost come to the end of the interview and I appreciate what I've learned from you so far. After our interview with you and other providers, we will have a better understanding of how IPV issues are being handled currently at the hospital. We will later conduct a larger study to really focus in on the feasibility of doing routine screening for IPV at the hospital. Would you be willing to participate in the larger study if we were to contact you for another interview?

9. Lastly, we also think it's important to set up a Hospital Research Task Force to sensitize hospital staff and administrators about the importance of this IPV study, as well as to help guide the study. If you had to nominate key persons at the hospital to be on such a task force, who would those key persons be?

\section{Interview Closing:}

That covers everything I wanted to ask. Thank you so much for your time. This has been very interesting and I've certainly learned a lot more about how IPV is handled at the hospital and what can be done to make routine screening for IPV a reality. 
CLIENT NUMBER

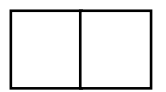

LOCATION OF VISIT

OBSERVER NAME

Time of client's arrival in clinic.

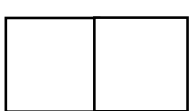

\section{CLIENT SERVICE TIME:}

Contact \#

\section{Contact}

Code

\begin{tabular}{|l|}
\hline 1 \\
\hline 2 \\
\hline 3 \\
\hline 4 \\
\hline 5 \\
\hline 6 \\
\hline 7 \\
\hline 8 \\
\hline 9 \\
\hline 10 \\
\hline 11 \\
\hline 14 \\
\hline
\end{tabular}

Start Time

Hour Min

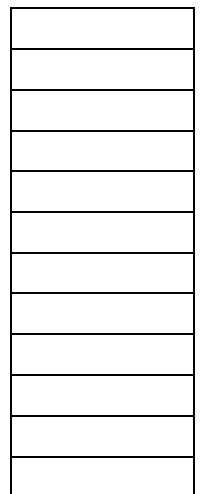

End Time

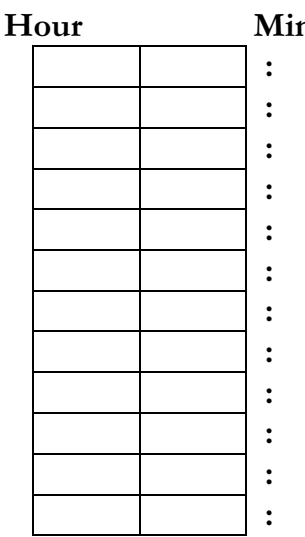

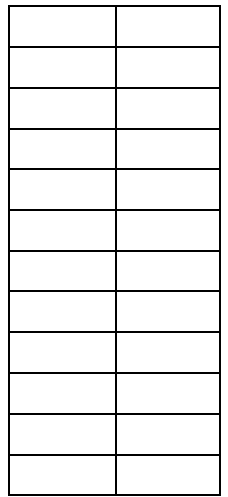

All times must correspond to those of a regular 24-hour clock

\begin{tabular}{|c|c|c|c|c|}
\hline \multicolumn{5}{|c|}{ CODE LIST } \\
\hline \multicolumn{2}{|c|}{ Information type } & Variable type & Code & Definition \\
\hline \multirow{9}{*}{\multicolumn{2}{|c|}{$\begin{array}{l}\text { 1. Contact - reflects } \\
\text { department or area } \\
\text { that client moves to } \\
\text { for each service }\end{array}$}} & \multirow{9}{*}{ Official designation } & A & Registration/reception \\
\hline & & & $\mathbf{B}$ & Weighing room/BP check room \\
\hline & & & $\mathrm{C}$ & Main Provider room (doctor, nurse) \\
\hline & & & $\mathbf{D}$ & $\begin{array}{l}\text { Counseling room (psychologist, counselor, } \\
\text { nurse counselor) }\end{array}$ \\
\hline & & & $\mathbf{E}$ & Laboratory \\
\hline & & & $\mathbf{F}$ & Pharmacy \\
\hline & & & G & Scanning/Imaging \\
\hline & & & $\mathbf{H}$ & Other (specify) \\
\hline & & & $\mathbf{I}$ & Referral (specify) \\
\hline \multicolumn{3}{|c|}{ LOCATION OF VISIT } & & \\
\hline Code & \multicolumn{2}{|l|}{ Definition } & & \\
\hline 1 & \multicolumn{2}{|l|}{$\mathrm{ANC}$} & & \\
\hline 2 & \multicolumn{2}{|l|}{$\mathrm{CCC}$} & & \\
\hline 3 & \multicolumn{2}{|l|}{ GBVRC } & & \\
\hline 4 & \multicolumn{2}{|c|}{ YOUTH CENTER } & & \\
\hline
\end{tabular}


For more information, contact:

\author{
Project Director \\ APHIA II OR Project in Kenya \\ Population Council \\ General Accident Insurance House \\ Ralph Bunche Road \\ P.O. Box 1764300500 \\ Nairobi, Kenya
}

Tel: 254202713480 - 3

Fax: 254202713479

www.popcouncil.org/projects/239_APHIAll.asp

(P Population Council 